\title{
Characterisation of Spray Development from Spark-Eroded and Laser-Drilled Multi-Hole Injectors in an Optical DISI Engine and in a Quiescent Injection Chamber
}

\author{
A.J. Butcher, P.G. Aleiferis \\ University College London, UK \\ D. Richardson \\ Jaguar Land Rover, UK
}

Copyright $\odot 2015$ SAE Japan and Copyright $\odot 2015$ SAE International

\begin{abstract}
This paper addresses the need for fundamental understanding of the mechanisms of fuel spray formation and mixture preparation in direct injection spark ignition (DISI) engines. Fuel injection systems for DISI engines undergo rapid developments in their design and performance, therefore, their spray breakup mechanisms in the physical conditions encountered in DISI engines over a range of operating conditions and injection strategies require continuous attention. In this context, there are sparse data in the literature on spray formation differences between conventionally drilled injectors by spark erosion and latest Laser-drilled injector nozzles. A comparison was first carried out between the holes of sparkeroded and Laser-drilled injectors of same nominal type by analysing their in-nozzle geometry and surface roughness under an electron microscope. Then the differences in their spray characteristics under quiescent conditions, as well as in a motoring optical engine, are discussed on the basis of highspeed imaging experiments and image processing methods. Specifically, the spray development mechanism was quantified by spray tip penetration and cone angle data under a range of representative low-load and high-low engine operating conditions ( 0.5 bar and 1.0 bar absolute, respectively), as well as at low and high injector body temperatures $\left(20^{\circ} \mathrm{C}\right.$ and 90 $\left.{ }^{\circ} \mathrm{C}\right)$ to represent cold and warm engine-head conditions. Droplet sizing was also performed with the two injectors using Phase Doppler Anemometry in a quiescent chamber.
\end{abstract}

\section{INTRODUCTION}

Improvements to the DISI combustion system are necessary to reduce fuel consumption and emissions, and enhancement of the fuel spray quality is crucial to realising those aims. Liquid fuel spray can impinge the piston and cylinder walls which can increase emissions e.g. particulates and unburned hydrocarbons, and contribute to oil dilution, carbon deposits and combustion instability. Increasing the vaporisation of the fuel and air-fuel mixture homogeneity, as well as reducing wall- wetting are crucial to improving the combustion processes in order to reduce particulate and other emissions, and is preferable to the reliance on after-treatment of the exhaust, with its associated cost and $\mathrm{CO}_{2}$ penalty.

A number of injector designs, with differing spray forms have been applied to the DISI engine. The first generation of DISI engines typically used pressure-swirl atomisers, and more recently the main type of injector that has received attention commercially and in research is the multi-hole injector. The enhanced atomisation characteristics of multi-hole injectors are well known and have been extensively studied in compression ignition engine applications. Multi-hole injectors represent state-of-the-art technology and are the principal choice for DISI engines due to their flexibility in fuel targeting and enhanced atomisation characteristics. The number and angles of nozzle holes can be varied and they perform well over a wide range of operating conditions.

Recent developments in multi-hole injector design have focused on the nozzle-hole geometry and new methods of producing the holes. Laser-drilled holes have superseded the typically spark-eroded nozzle holes (called spark-drilled for consistency hereafter), with the former said to provide higher flexibility of nozzle hole geometry e.g. shaping to promote or suppress turbulence and cavitation [1]. Laser-drilled nozzles can have reduced surface roughness and simplify injector manufacturing by circumventing the need for abrasive flow machining, as is often used in the manufacture of high pressure injectors for $\mathrm{Cl}$ engines. There is a dearth of literature concerning Laser-drilled injectors' spray performance and the limited experimental results that can be found show a reduction in particulate mass and number for some injection strategies. In one such work, for twin injection, the particulate number reduced by one third and particulate mass by one half and for a triple injection strategy the particulate number reduced by more than one third and the mass by one half, but a reduction was not seen for a single injection [2]. More recent work compared spark and Laser-drilled multi-hole injectors with equivalent exterior hole geometry but of varying length-to- 
diameter $(L / D)$ ratios, in a single cylinder optical engine. It found that Laser-drilled injector nozzles with lower L/D ratios have a totally 'collapsed' fuel spray structure (towards the injector body axis) with increased spray penetration resulting in severe fuel impingement and rapidly forming soot deposits on the piston. The collapsed spray plumes vaporised more slowly and resulted in rich zones which led to significantly increased soot luminosity compared to the spark-drilled injector [3].

\section{Present Contribution}

There are very limited data on latest design Laser-drilled injectors, especially in direct comparison with their spark-drilled 'equivalent' types, and in the context of spray characterisation. The current study is aimed at filling this gap in the literature by providing new experimental data from two six-hole injectors of nominal 'like-for-like' replacement type featuring different nozzle-hole manufacturing processes. The objectives of the paper are summarised as follows:

- Analysis of the in-nozzle hole geometry and surface of the two injectors by scanning electron microscopy and quantification of their characteristics.

- High-speed imaging of the spray formation mechanism of the two injectors in a quiescent air environment and in a running optical DISI engine at different engine cylinder head temperatures.

- $\quad$ Droplet sizing of the sprays produced by the two injectors at different injector temperatures and gas pressures and representative of high-load and low-load engine operating conditions using Phase Doppler Anemometry.

\section{EXPERIMENTAL TECHNIQUES AND METHODOLOGY}

\section{Injector Types and Geometry}

The basis of the current study is the comparison of two previously unused solenoid actuated multi-hole valve covered orifice (VCO) injector types, where their six holes are drilled using two different techniques; one was drilled by eroding the six injection holes using spark discharge, also known as electrical discharge machining (EDM), and the other was drilled using a Laser to erode the six injection holes. The Laser-drilled injector was supplied with the claim that it is a 'like-for-like' replacement for the spark-drilled nozzle. A schematic of the six spray plumes of the multi-hole injectors is shown in Fig. 1. The nozzle hole configuration was designed to be orientated so that the spark plug electrode is located between plumes 1 and 6, Fig. 1(b), when viewed from the base. The location of the engine's intake and exhaust side with respect to the plumes' pattern and orientation has also been indicated in Fig. 1(b) for completeness.

Microscope images of one of the six holes for both injector types are shown in Fig. 2 and Fig. 3 and it can be seen that the individual injection holes are counterbored and so have different diameters. Both nozzles have a smaller diameter inlet hole which expands to a larger diameter outlet hole. Deposit formation tendency and associated issues of injection nozzle Page 2 of 22 coking and fuel flow rate degradation are generally mitigated by this counterbored outlet section for DISI combustion systems [4] However, the exact detailing of this geometric feature can also affect the primary spray formation, not only due to the diameter increase but also because each nozzle hole has two outlet edges and in-nozzle multi-phase flow phenomena are extremely complex [5, 6]. Diameter measurements were taken using an in-built function of the microscope and verified in detail using imaged micrometer Vernier scales.
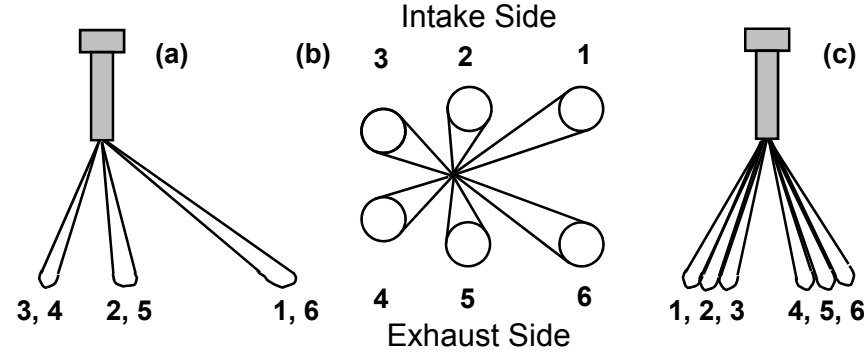

Fig. 1. Schematic of multi-hole injector spray pattern and plume numbers: (a) exhaust side view, (b) piston view, (c) tumble view.

Fig. 2 and Fig. 3 show that the larger diameter holes at the nozzle outlet have similar dimensions of approximately 0.45 $\mathrm{mm}$ diameter for both the spark-drilled and Laser-drilled injectors. Specifically, this was found to vary around the hole in the region $0.44-0.45 \mathrm{~mm}$ for the spark-drilled injector, but it was of better roundness tolerance around $0.45 \mathrm{~mm}$ for the Laser-drilled. The Laser-drilled injector's outlet hole edge in Fig. 3 also appears to have, apart from improved roundness, a better defined edge compared to the spark-drilled injector's outlet hole in Fig. 2 (it is known that sharper outlet edges can promote increased breakup of the exiting fuel). However, the smaller holes of the inlet had different dimensions at the location where the smaller diameter hole expanded to the larger outlet hole. The Laser-drilled injector's inner hole in Fig. 3 measures approximately $0.25 \mathrm{~mm}, 25 \%$ larger diameter than the spark-drilled injector in Fig. 2, which measures $\sim 0.20 \mathrm{~mm}$ at the location the inner nozzle's expansion.

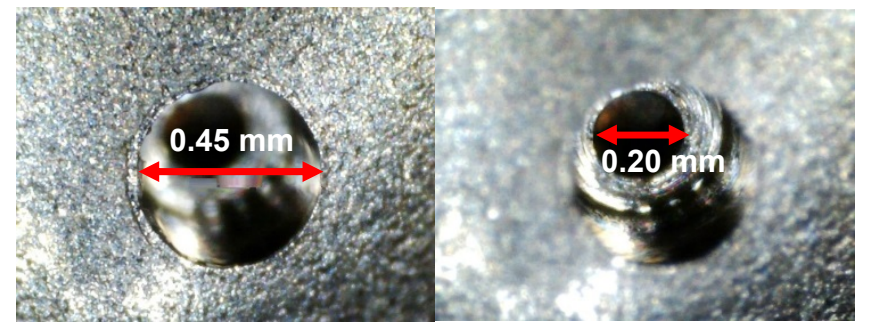

Fig. 2. Spark-drilled injector. One of six holes, outer and inner hole.

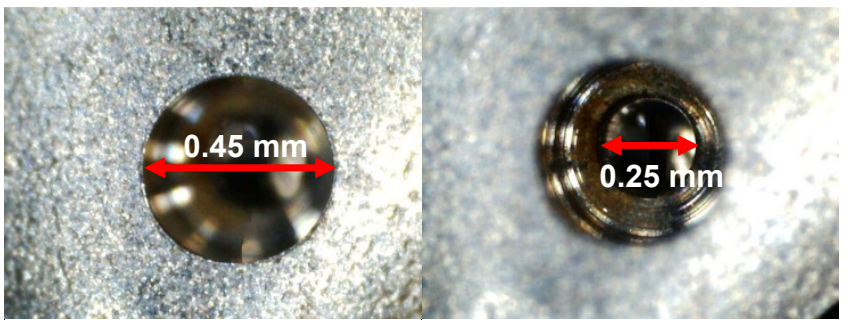

Fig. 3. Laser-drilled injector. One of six holes, outer and inner hole. 


\section{Scanning Electron Microscope Analysis}

A scanning electron microscope was used for a detailed investigation of the internal geometry of the spark and Laserdrilled nozzle holes. To facilitate the analysis, impressions were made of the internal surfaces of the nozzle holes using a specially formulated low viscosity silicone impression material called Vinyl-Poly-Siloxane (VPS), the same material used for taking high accuracy dental and archaeological surface impressions, using a similar technique according to [7] and [8]. The VPS is a two-part addition-reaction material which, after mixing, fills the nozzle hole void and cures in minutes to form a detailed and accurate 'negative' impression of the nozzle hole's geometric and surface roughness characteristics. The particular VPS material that was used features an elastic recovery of $>99.5 \%$ and linear dimensional change of $<0.2 \%$ (in $24 \mathrm{hrs}$ ).

The negative impressions were plasma-coated with a very thin layer of gold to make the material electrically conductive for the electron microscope. Results from the analysis are shown in Fig. 4 and Fig. 5 for the spark and Laser-drilled nozzle holes, respectively.

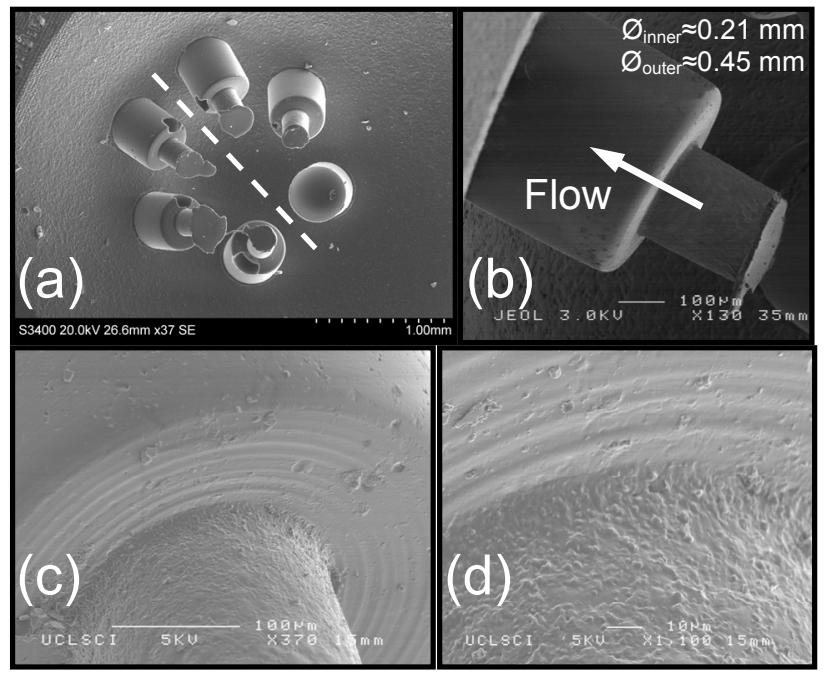

Fig. 4. Electron microscope images of negative VPS impressions of the spark-drilled injector.

Fig. 4(a) shows the six-hole spark-drilled nozzle configuration with a dashed line showing the plane of symmetry separating the plume pairs. One of the six nozzle holes was not cast properly due to a trapped air bubble, which was difficult to avoid as the VPS material was introduced at the nozzle outlets and displaced air may not adequately flow past the ball-end needle valve located at the nozzle inlet. The thin casting flash seen at the nozzle inlets, towards the centre of the image, blocks the view of many of the nozzle inlets, and is due to the VPS flowing upstream of the inlet edges and stopped by the ball-end needle valve. Fig. 4(b) shows one of the six nozzle holes which has a diameter of approximately $0.21 \mathrm{~mm}$ at the inlet region and $0.45 \mathrm{~mm}$ at the outlet region and it can be seen that the nozzle inlet's smaller diameter orifice channel length varies around the surface. Fig. 4(c) shows the surfaces of the smaller diameter nozzle inlet and the larger diameter nozzle outlet, at the location of the step between the two. The roughness of the surface of the smaller diameter hole is significantly more than the surface of the larger hole. Also, at the location of the step, concentric rings were seen on the surface and were probably the result of scoring by a rotary machine tool and may also explain the otherwise smoother surface of this downstream nozzle section, compared to the pitted surface of the smaller diameter nozzle inlet section. The relatively rough pitted surface was caused by localised melting during the spark drilling process. Fig. 4 (d) is a magnified view of Fig. 4 (c) and shows the relatively rough pitted surface of the inlet hole which has a surface roughness of a size scale between approximately 1 to over $3 \mu \mathrm{m}$ in some regions. Further electron microscope images of this particular sparkdrilled injector can be found in [8].

Fig. 5 shows that the Laser-drilled injector nozzles are significantly different in shape, size and surface roughness compared to the spark-drilled injector nozzles in Fig. 4, particularly at the smaller diameter inlet region, before the step expansion towards the nozzle's outlet. Fig. 5(a) shows the sixhole configuration with dashed line indicating the plane of symmetry. The dark regions of the bottom two nozzles were caused by trapped air bubbles. Thin casting flash at the location of the nozzle inlets can be seen, similar to the sparkdrilled nozzle of Fig. 4(a).

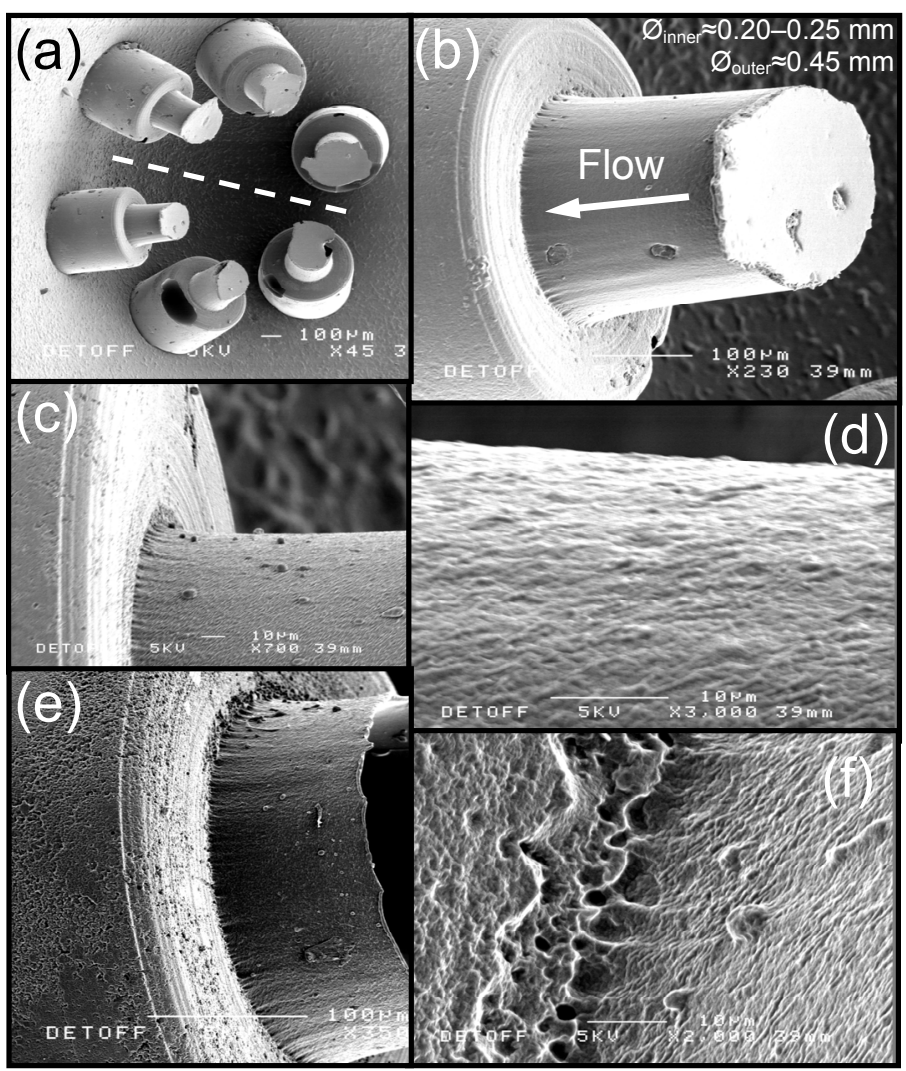

Fig. 5. Electron microscope images of negative VPS impressions of the Laser-drilled injector.

Fig. 5(b) shows one of the six nozzles which corresponds to plume number six (Fig. 1) and it can be seen that the Laserdrilled hole diverges from approximately $0.2 \mathrm{~mm}$ diameter at the nozzle inlet to approximately $0.25 \mathrm{~mm}$ diameter at the location immediately before the step transition, to 
approximately $0.45 \mathrm{~mm}$ outlet diameter. Fig. 5(c) shows a magnified view of the smaller inlet hole and the step expansion to the larger outlet hole. In this region a larger radius of curvature than the spark-drilled injector was observed immediately upstream of the step expansion which can reduce flow separation and affect the spray formation and breakup. Fig. 5(d) shows a high magnification image of the Laser-drilled nozzle's inlet surface characteristics and it can be seen that the surface roughness is significantly less than the sparkdrilled nozzle surface's in Fig. 4. The Laser-drilled surface variations appear to be in the sub-micrometer range for the majority of the surface until the region of the step change to the larger outlet diameter where it can be seen in Fig. 5(e) that relatively large scale furrows exist in the Laser-drilled nozzle's surface, and appear to become shallower towards the nozzle's inlet. Fig. 5(f) is a high magnification image of the location where the Laser-drilled nozzle inlet surface step transitions to the larger diameter downstream section and, although no large furrows can be seen in this particular image, it shows that the hole's edge has higher roughness than the majority of the Laser-drilled surface and is likely an artefact left from the Laser drilling technique, perhaps due to the Laser beam's crosssectional geometry. A schematic detailing general dimensions of the two nozzle types is shown in Fig. 6 to avoid ambiguities. The ratio length to diameter $L / D$ of the inlet and outlet sections varies in the region 1.0-1.5.
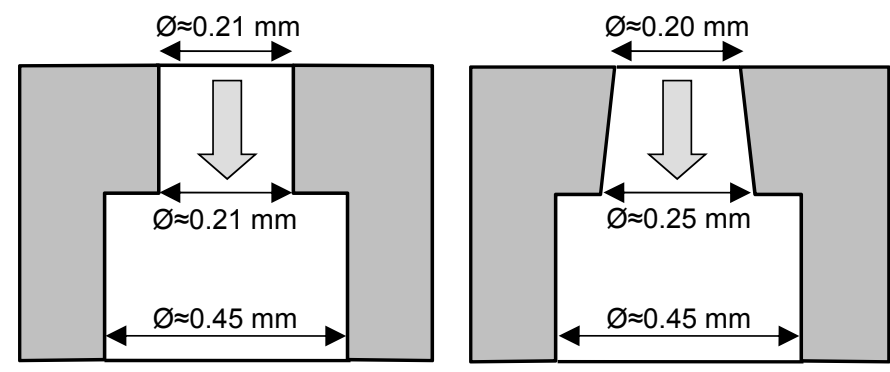

Fig. 6. Schematic of general geometry of spark-drilled nozzle hole (left) and Laser-drilled nozzle hole (right).

In summary, there are significant differences between the spark and Laser-drilled injector nozzles:

- Although both injector types have a similar nozzle inlet diameter of approximately $0.2 \mathrm{~mm}$, the Laser-drilled nozzle diverges to approximately $0.25 \mathrm{~mm} \quad(>50 \%$ flow area increase) at the location where the smaller inlet channel step transitions to the larger outlet section, unlike the sparkdrilled nozzle which has parallel-walled channel.

- The divergent channel characteristic of the Laser-drilled injector is likely to affect in-nozzle flow characteristics e.g. reduced pressure, velocity, and promotion of cavitation along the nozzle length [9]. Also the divergent nozzle has a more acute inlet angle than the non-divergent case which may lead to increased flow separation at the nozzle inlet e.g. vena-contracta, and the separated flow may not reattach to the nozzle wall until further downstream, or reattachment may be prevented entirely.

- The larger diameter nozzle outlet sections were similar for both injector types in terms of diameter and channel length and there appears to be a similar hole-to-hole variation, which is dependent on the angle of drilling of the individual holes. Nozzle holes corresponding to plume 1 and 6 (Fig. 1) have the longest channel length owing to the larger drilling angle (referenced to the injector body axis).

- Inlet and outlet sections of both injector types Length/Diameter (L/D) appear to be between 1 and 1.5, dependent on the hole. It is challenging to determine L/D differences between the injector types and also may not be appropriate due to key geometrical differences that would require averaging i.e. the divergence of the Laser-drilled inlet section, the nozzle holes each have two distinct sections separated by a step feature and also the channel lengths vary from hole-to-hole and can also vary for a single hole (e.g. spark-drilled nozzle channel has longer lower wall than upper wall in Fig. 4(b)).

- The Laser-drilled nozzle has a larger radius of curvature at the step transition to larger diameter hole which is likely to result in less flow separation downstream. The radius of curvature of the most downstream nozzle edge where the fuel exits the injector tip is likely to be similar for both injectors as it appears that a similar machining process was used for drilling the larger downstream section of the nozzle, although optical microscope images show better nozzle outlet roundness than the spark-drilled nozzle.

- The Laser-drilled nozzle has significantly reduced surface roughness which can affect the flow in terms of reducing flow friction, turbulence and boundary layer thickness which may serve to increase the discharge coefficient. Also it may affect the propensity for in-nozzle cavitation as it is known that surface roughness can have a marked effect on phasechange phenomena - nucleation being promoted on surfaces with increased roughness.

\section{Injected Fuel Mass}

The engine/fuelling control module varies the mass of the fuel injected primarily by varying the electrical pulse width control input to the injector. The same fuel control module and calibration maps were used for all tests in this work, similar to those used in serial production vehicles. The control strategy was modified to act as a stand-alone unit. The injector timing and actuation pulse width were supplied to the fuel control module with an AVL 427 engine timing unit. Equivalent pulse widths for both injector types were used for this investigation based on the premise that they are like-for-like replacements and the Laser-drilled injector can be substituted with minimum need for re-calibration of the fuelling and spark control. It is therefore important to quantify differences of injected fuel mass as it should not be assumed that both nozzle types inject the same fuel mass for equivalent electrical pulse input and it is important any differences are accounted for in the analysis. Only one specimen of each type was tested and comments on potential injector-to-injector variations are made later.

The injected fuel mass of both injector types was gravimetrically measured for varying electrical actuation pulse widths. The fuel from all six nozzle holes was injected into atmospheric downstream pressure, into a sealed variable volume receptacle (similar to a collapsed bag) for 200 injection events. The fuel was weighed on an electronic scale that has 
an accuracy of $0.001 \mathrm{~g}$ and the average fuel mass per injection was found. Fuel mass measurements were found to be very repeatable; usually within $0.1 \mathrm{mg}$ and up to $0.2 \mathrm{mg}$, on average, for a single injection. The injector types were compared at injector body temperatures of $20{ }^{\circ} \mathrm{C}$ and $90{ }^{\circ} \mathrm{C}$ using gasoline at 150 bar injection pressure (this pressure was used throughout the current work). The distillation curve of the gasoline that was used has been presented elsewhere and not reproduced here for brevity [10-12].

The injector was mounted into an Aluminium block, acting as a thermal mass, and instrumented with a thermocouple inside the block, close to the injector tip. A band heater was secured onto the block and closed-loop controlled to the desired temperature. It is noted that temperatures quoted hereafter are those of the injector body and not fuel temperature within the nozzle, which may be higher at some conditions e.g. full load. Nevertheless, it remains an important parameter due to the use of cylinder head temperatures (head coolant/metal or both) as an important input variable in fuel control calibration.

The injected fuel mass results for gasoline are shown in Fig. 7. It is observed that the Laser-drilled injector injects higher fuel mass than the spark-drilled injector at both temperature conditions. The greatest injected fuel mass difference between the injectors was at 150 bar, $90{ }^{\circ} \mathrm{C}$ where the Laser-drilled nozzle injects up to $1.7 \mathrm{mg}$ more per injection and up to almost $6 \%$ more fuel than the spark-drilled injector, depending on the injector pulse width. The consistently increased fuel flow for the Laser-drilled injector at both $20^{\circ} \mathrm{C}$ and $90{ }^{\circ} \mathrm{C}$ indicates that the differences in nozzle geometry (potentially including differences of needle valve lift) are the primary driver for the increased fuel mass. These observed fuel mass differences may be mitigated by the closed loop fuelling control strategy based on exhaust gas oxygen sensing, employed at part load engine conditions. However, operating regions where open loop fuelling control strategies are employed (e.g. at full load and cold start) may exhibit differences in combustion and emissions (e.g. increased soot) between the two injector types. This can be avoided when updated injector fuel mass 'pulse maps' are re-calibrated within the fuel control module.

The reasons for the increased fuel mass of the Laser-drilled injector are not clear. The lower losses can be the result of contribution from a number of the geometric differences between the injectors, (shown previously in Fig. 4 and Fig. 5). The Laser-drilled injector has a significantly lower surface roughness which will serve to reduce viscous losses. Also, although the nozzle inlet flow areas are similar, the Laserdrilled injector nozzle diverges and this may serve to expand the flow's stream lines and 'relax' the velocity profile as the flow area increases and so decrease viscous losses. Also innozzle cavitation effects are likely to be influenced by the divergent nozzle walls, in which case they are likely to be enhanced [9].

It is also possible that the higher fuel mass of the Laser-drilled nozzle is in some part due to increased inlet radii and/or needle lift, compared to the spark-drilled nozzle. The sparkdrilled nozzle's needle lift was measured using a spare injector which was cut open and the needle movement measured with a high speed camera, long distance microscope and Vernier scale. The lift was found to be approximately $40 \mu \mathrm{m}$. The needle lift of the Laser-drilled injector was not measured within the bounds of this exercise due to confidentiality issues.

\section{Gasoline $20^{\circ} \mathrm{C}$}

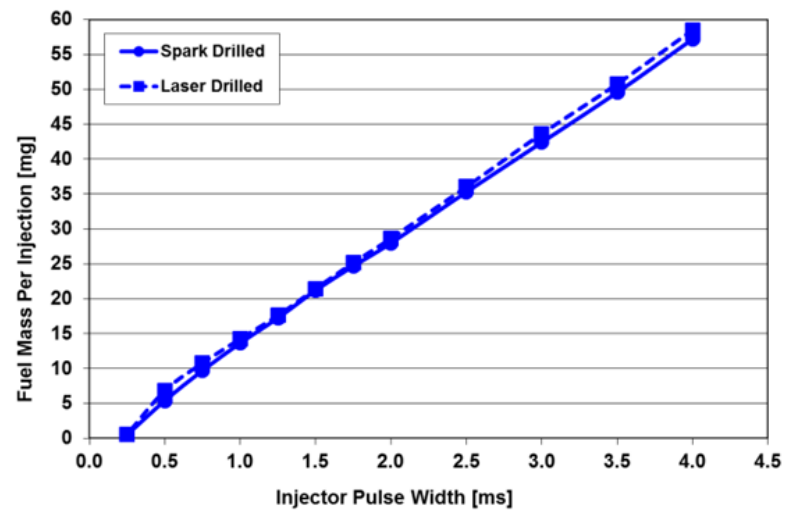

Gasoline $90^{\circ} \mathrm{C}$

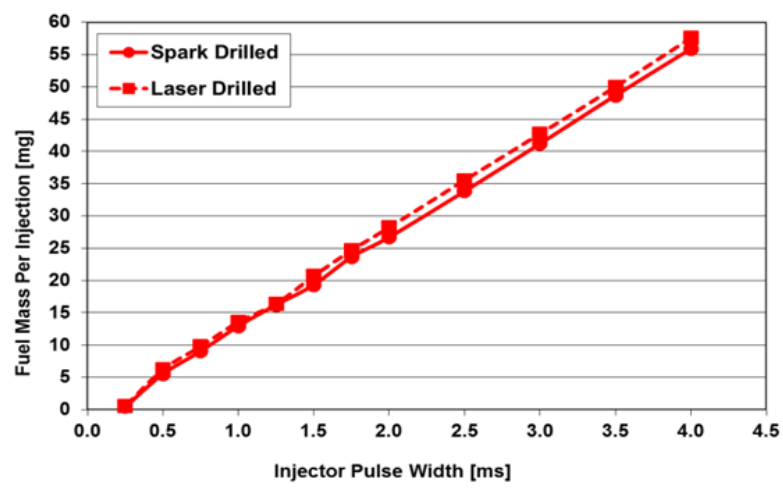

Fig. 7. Average gasoline mass per injection for spark and Laser-drilled injectors, $20^{\circ} \mathrm{C}$ (top) and $90{ }^{\circ} \mathrm{C}$ (bottom) injector body temperatures.

At $90{ }^{\circ} \mathrm{C}$ (Fig. 7) there was a small reduction of fuel mass (1$1.5 \mathrm{mg}$ ) for both injector types which is due to the combined effect of the various fuel property changes, which can have competing contributions to overall fuel flow differences. At elevated temperatures there was a reduction of fuel density which will reduce the injected fuel mass for the same volume flow rate. However, at the same time the volume flow rate may also be increased due to lower viscosity, which serves to increase the fuel mass and competes with the density reduction. Furthermore, the reduction of viscosity also increases the turbulence of the flow within the nozzle, and so a higher propensity for cavitation exists (which occurs in the regions where the local pressure falls to below the fuel's vapour pressure, for the prevailing local temperature conditions), leading to a two-phase flow field within the nozzle. An increased vapour fraction and reduction of the effective liquid flow area reduces the injected fuel mass. It is challenging to measure or predict the change of density of gasoline with respect to temperature and there is a dearth of empirical data as measurement is made difficult by a significant proportion of components which have boiling points lower than $90{ }^{\circ} \mathrm{C}$ (at atmospheric pressure). The spark-drilled injector showed a slightly greater reduction of fuel mass than for the Laser-drilled nozzle at the higher temperature which may indicate higher viscous losses or increased cavitation or perhaps a combination of both. 
Although it may be argued that the observed fuel mass differences may be within part-to-part variation, the authors think this is unlikely. In support of differences being mainly due to drilling technique, another paper of our research group [13] also found that the Laser-drilled nozzle injected higher fuel mass compared to the spark-drilled equivalent (7-hole injectors with $10 \%$ observed difference). It is also noted that the work of [14] characterised a population of 25 multi-hole DISI injectors, used in the Ford EcoBoost engine, and found that (at 100 bar) the shot-to-shot coefficient of variation was mostly $<0.3 \%$ and the part-to-part variation was $\sim 1.5 \%$ at similar pulse widths used in the current study (1.4 $\mathrm{ms}$ and $2 \mathrm{~ms})$. This brings the larger flow differences measured here between the sparkdrilled and Laser-drilled injectors into perspective.

\section{Single-Cylinder Optical Engine}

The Laser and spark-drilled injector sprays were analysed in a static and motored optical engine. The engine is shown in Fig. 8 , and geometrical details are summarised in Table 1. Further information on this engine and can be found in previous publications and are not repeated here for brevity [15-20].

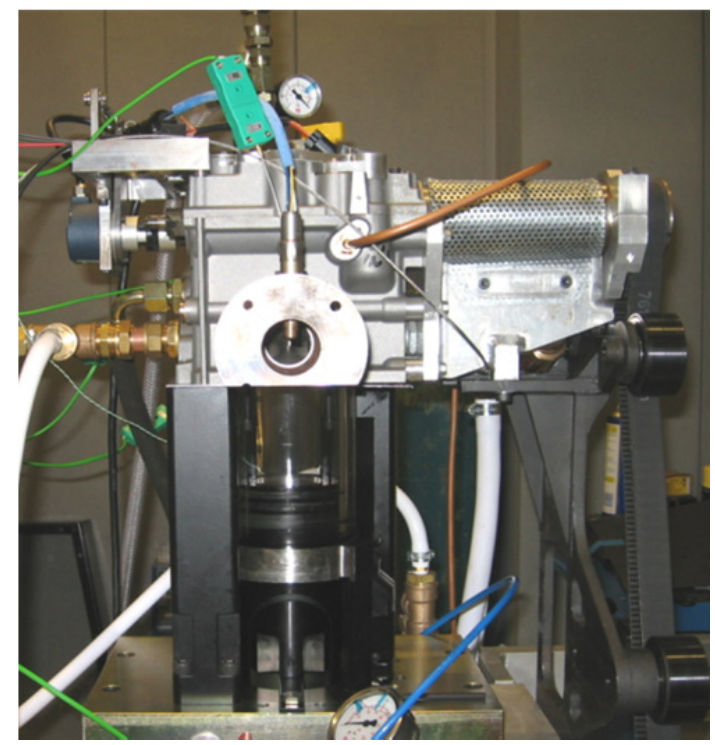

Fig. 8. Optical engine.

Table 1. Engine specifications.

\begin{tabular}{|l|l|}
\hline Engine Type & 4-Stroke, Pentroof type, Central DI \\
\hline Cylinders, Valves & $1,4(2$ Intake, 2 Exhaust) \\
\hline Bore, Stroke & $89.0 \mathrm{~mm}, 90.3 \mathrm{~mm}$ \\
\hline Compression Ratio & $11.15: 1$ \\
\hline $\begin{array}{l}\text { Valve Timings (Maximum } \\
\text { Opening Position) }\end{array}$ & $\begin{array}{l}\text { Inlet: } 129^{\circ} \mathrm{CA} \text { after intake TDC } \\
\text { Exhaust: } 86^{\circ} \mathrm{CA} \text { before intake TDC }\end{array}$ \\
\hline
\end{tabular}

The static tests used the engine as a spray chamber, decoupling airflow effects and facilitating detailed analysis of the individual spray plumes. Also, Injectors are often characterised and specified using a quiescent injection chamber owing to the significantly reduced cost and complexity compared to using optical engines, and so the spray differences between static Page 6 of 22 and motored engine conditions are important to ascertain. The static images are useful also because the valves and bore limit are shown. High speed imaging data were acquired with a Photron APX-RS high-speed camera at 9000 frames per second (resolution $111.111 \mu \mathrm{s}$, equating to exactly $1^{\circ} \mathrm{CA}$ at $1500 \mathrm{RPM}$, or to $1.166^{\circ} \mathrm{CA}$ at the $1750 \mathrm{RPM}$ used throughout the current work). A shutter duration of $1 \mu$ s was employed and a Multiblitz high intensity discharge flash lamp was used as the light source. Fuel temperature was increased using a closedloop controlled coolant and heating system to increase the cylinder head and injector body temperature to the desired level. Injection timing was controlled with an AVL 427 engine timing unit. The injector pulse width input was set to $1.4 \mathrm{~ms}$ for all engine tests.

Instantaneous (single-shot or single-cycle) spray images from both injectors, mean spray images, subtraction between the respective mean images of the spark-drilled and Laser-drilled injector, as well as coefficient of variation (CoV) spray images are presented and compared. Two camera views (piston and exhaust side view) of both injectors for static (quiescent) and dynamic (motored engine) cases were analysed, at $20^{\circ} \mathrm{C}$ and $90{ }^{\circ} \mathrm{C}$ injector body temperatures. The camera was triggered at the start of injector input pulse and 30 images were acquired per cycle. Motored piston view data were acquired for 100 cycles and the exhaust view and static engine tests were acquired for 40-50 cycles. The optical engine cannot be motored for more than 2-3 minutes due to heat build at the optical liner/piston ring (Torlon $\AA$ material) interface. Between 30-40 non-consecutive cycles could be acquired per test run. Unfortunately more was not possible due to the nature of operation of high intensity discharge lamps, specifically the time taken for associated electronics (i.e. capacitors) to recharge prior to the light discharge.

Spray images were formed by the scattered light reflected from liquid fuel droplets according to the Mie scattering theory. The amount of light scattered by a droplet is proportional to its surface area and so increases with the square of the droplet diameter. The intensity of scattered light from the total surface area of all droplets can be linked to liquid fuel concentration although it should be noted that scattered light intensity increase can be the result of either larger droplets or a higher number of smaller droplets and so droplet size information cannot be deduced from a global spray image of this type. It should be noted that the light source originates from the left of the images and so spray features in the left region are associated with higher light intensity than spray features in the right region. However, testing showed that the higher light intensity on the left side did not mask features of the spray on the right side when processed, i.e. the results are independent of side of light entrance.

\section{Image Processing Methodology}

An in-house MATLAB program code was modified to batch process the spray image data and to perform statistical analysis. Mean average, standard deviation and co-efficient of variation images were derived for up to 100 engine cycles for 30 frames per cycle, at $111 \mu$ s intervals, from the start of injection trigger. The number of pixels in each image was $640 \times 480$ and the pixel values range from 0-255 (8 bit). The processed images were 'false' coloured to better show differences of level of light. The processed images were used 
to obtain spray penetration and cone half-angle for the exhaust view which necessitated threshold operations to define the spray region from the no-spray region. Analysis of image intensity for each batch was performed to normalise threshold selection based on the maximum light intensity, on a frame-byframe basis, and also revealed the signal-to-noise ratio limit of thresholding. Image masking operations were also required to circumvent reflections from the glass liner. Due to the flashlamp having a low rate of repetition, obtaining 100 cycles required batches from multiple test runs to be linked together and often spatially shifted prior to the statistical analysis. The spray penetration and angle analysis was hindered because the injector tip could not be seen in the images, due to the glass liner extending only to piston TDC. Although the pentroof view could have been selected, the exhaust-side view was preferable as it allowed a larger number of plumes to be visualised. Therefore, it was required to 'virtually peg' the location of the injector tip, relative to each image batch.

\section{Phase Doppler Anemometry}

A TSI Phase Doppler Anemometry (PDA) system using a Coherent Innova 70C Laser was used to analyse the droplet sizes of the two injector types in a quiescent injection chamber. Details of the injection chamber used have been published earlier and are not repeated here for brevity. The reader is guided to [10-12] for further details. To investigate whether there were significant droplet size differences between the two injectors, tests were carried out $25 \mathrm{~mm}$ vertically downstream from the tip of the injector. It was not practical to measure closer to the injector tip due to the signal attenuation from the high density spray plume core. One of the centre plumes (number 5, shown in fig. 1) was isolated with a metal plate with a v-shaped cut, which was restrained to restrict movement. Images of the isolated spray plume were acquired with a high speed camera to ensure the isolation plate did not move and the nozzle's other plumes did not interact with the isolated plume. The injector was orientated so the system's measurement volume traversed in a straight line from the inner edge (closest to the injector body axis), through the spray centre and to the opposite outer spray edge (closest to the cylinder bore) of the isolated spray plume. Measurements were made at equidistant points along the horizontal line, typically at 11-13 location points, dependent on PDA data rate. The distance between each point was $1.27 \mathrm{~mm}$, i.e. typically scanned across $\sim 13-16 \mathrm{~mm}$ of the plume, as shown in Fig. 9.

Droplet size data were acquired for 200 injections to ensure a large number of valid droplet measurements, leading to approximately $10,000-20,000$ valid droplet data counts at each measurement location. The actual number of valid data counts were dependent on the measurement location; there were a high number at the outer regions of the spray (sometimes $>20 \mathrm{~K}$ ) and a lower number at the centre of the spray plume (sometimes <10K) due to the increased signal attenuation in the dense spray plume core. Droplet size data are presented for the periods until $4 \mathrm{~ms}$ ASOI (which includes the whole spray event and later spray breakup and evaporation) and until $1 \mathrm{~ms}$ ASOI (which focuses on the spray tip and initial spray breakup). PDA data quality can be significantly affected by various system settings and so detailed tests were carried out initially using considerable in-house expertise in order to identify the most appropriate set of parameters for this measurement campaign.

Page 7 of 22

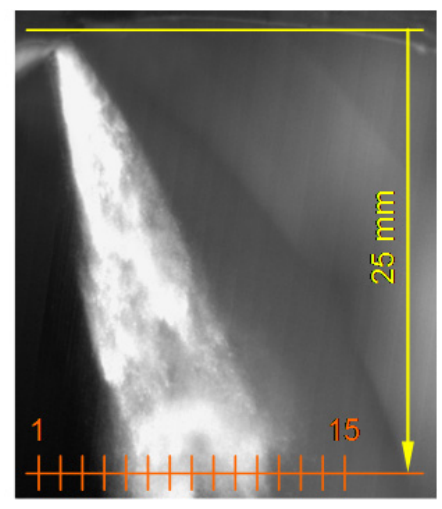

Fig. 9. Spray image and superimposed PDA measurement locations.

The two injectors were characterized at $20{ }^{\circ} \mathrm{C}$ and $90{ }^{\circ} \mathrm{C}$ injector body temperature injecting into 1.0 bar and 0.5 bar downstream air pressure. The injection chamber was purged for $2 \mathrm{~s}$ after each injection event and time allowed for settling of residual airflow before the next injection. To save time and to achieve measurement consistency an in-house programmed control system, interfaced with an AVL 427 engine timing unit running in simulator mode, was used to synchronise the injection, PDA data acquisition trigger, and purging events. The Laser power was regularly checked throughout the tests. Further details on the PDA methodology and uncertainties have been discussed elsewhere [12, 21].

\section{RESULTS AND DISCUSSION}

The instantaneous piston and exhaust side view images of the spray in a static and motored engine are shown in Fig. 10, Fig. 11 and Fig. 18, Fig. 19, respectively. The instantaneous images represent a typical single injection event. A mean spray image at each test condition is included for comparison and completeness in Fig. 12, Fig. 15 and Fig. 20, Fig. 22, where it can be seen that some of the individual spray details were inevitably lost, particularly at the edges of the spray. In contrast, the CoV data of Fig. 14, Fig. 17 and Fig. 21, Fig. 23 highlight the outer periphery/edges of the spray where the shot-to-shot/cycle-to-cycle variation of the leading edge was much higher than at the sides and the core of the plumes and so were useful for determining the region where the edge of the spray is likely to have existed. The CoV was considered to be more useful than the standard deviation because the data were normalised to the mean light intensity and so potential influence of light variations between sets was reduced.

\section{Static Engine Tests}

The instantaneous, mean, subtraction of mean images and CoV results of the injector comparison in the static engine are shown in Figs. 10-17, where it can be observed that fuel was first seen at $333 \mu$ s (temporal resolution: $111 \mu \mathrm{s}$ ) after start of injection trigger for both injector types. The instantaneous images in Fig. 10 and also the mean images in Fig. 12 show that at $20^{\circ} \mathrm{C}$ the Laser-drilled injector's spray plumes appear to be more diffuse and also have a reduced horizontal spray penetration compared to the spark-drilled nozzle, throughout the spray event. At $90{ }^{\circ} \mathrm{C}$ increased width and greater interaction of the individual spray plumes of the Laser-drilled injector nozzle were also seen, however differences of horizontal spray penetration were not so marked. 
Fig. 13 shows mean image subtraction results which quantify and highlight regions of spray differences between the injector's spray types; the left column at each temperature shows the mean spark-drilled spray after subtraction of the Laser-drilled spray and the right column the Laser-drilled spray minus the spark-drilled one. At $20{ }^{\circ} \mathrm{C}$ the spark-drilled injector difference shows higher liquid fuel concentration at the spray tips and the Laser-drilled injector difference shows the regions of more diffuse spray. At $90{ }^{\circ} \mathrm{C}$ the spark-drilled injector difference image again shows a higher liquid fuel concentration at the spray tips and retains distinct individual spray plumes. The Laser-drilled injector difference image highlights the more diffuse spray and increased liquid fuel concentration centrally. Fig. 14 shows the CoV of the Laser-drilled nozzle spray has a larger region of variation (spatially) at the spray edges, especially at $90{ }^{\circ} \mathrm{C}$, which indicates a more diffuse spray edge. Fig. 10 shows that at $90{ }^{\circ} \mathrm{C}$ the Laser-drilled injector nozzle appears to have a higher density of spray towards the centre of the image compared to the spark-drilled injector which can be explained with the aid of the instantaneous and mean exhaust side view images of Fig. 11 and Fig. 15. At $90{ }^{\circ} \mathrm{C}$ the Laserdrilled injector's individual plumes appear to collapse in on each other towards the centre of the image (injector body axis), and is distinctly different to the spark-drilled injector which does not show a prominent spray collapse at these quiescent static engine conditions. The side view images of Fig. 11 and Fig. 15 also show that the Laser-drilled nozzle appears to have a more acute spray cone angle (referenced to the vertical) than the spark-drilled nozzle, not only for the case of spray collapse but also at the lower temperature where the spray plumes do not collapse. The mean image subtraction results of Fig. 16 show the difference between the injector spray types and highlight the Laser-drilled injector's more acute spray cone angle at both temperature conditions and also the collapsed spray at $90^{\circ} \mathrm{C}$. Fig. 11, Fig. 15 and Fig. 17 at $20^{\circ} \mathrm{C}$ show increased vertical spray penetration of the Laser-drilled injector, compared to the spark-drilled injector. However, at $90{ }^{\circ} \mathrm{C}$ where the Laserdrilled nozzle's spray collapses and the individual plumes have higher interaction with each other, reduced vertical penetration was observed for the Laser-drilled injector, despite the expected increase of vertical velocity component of the collapsed plumes. This indicates increased evaporation and momentum exchange with surrounding air at the quiescent condition, compared to the non-collapsed spark-drilled spray. Spray penetration and cone angles are quantified and discussed in later sections of this paper.

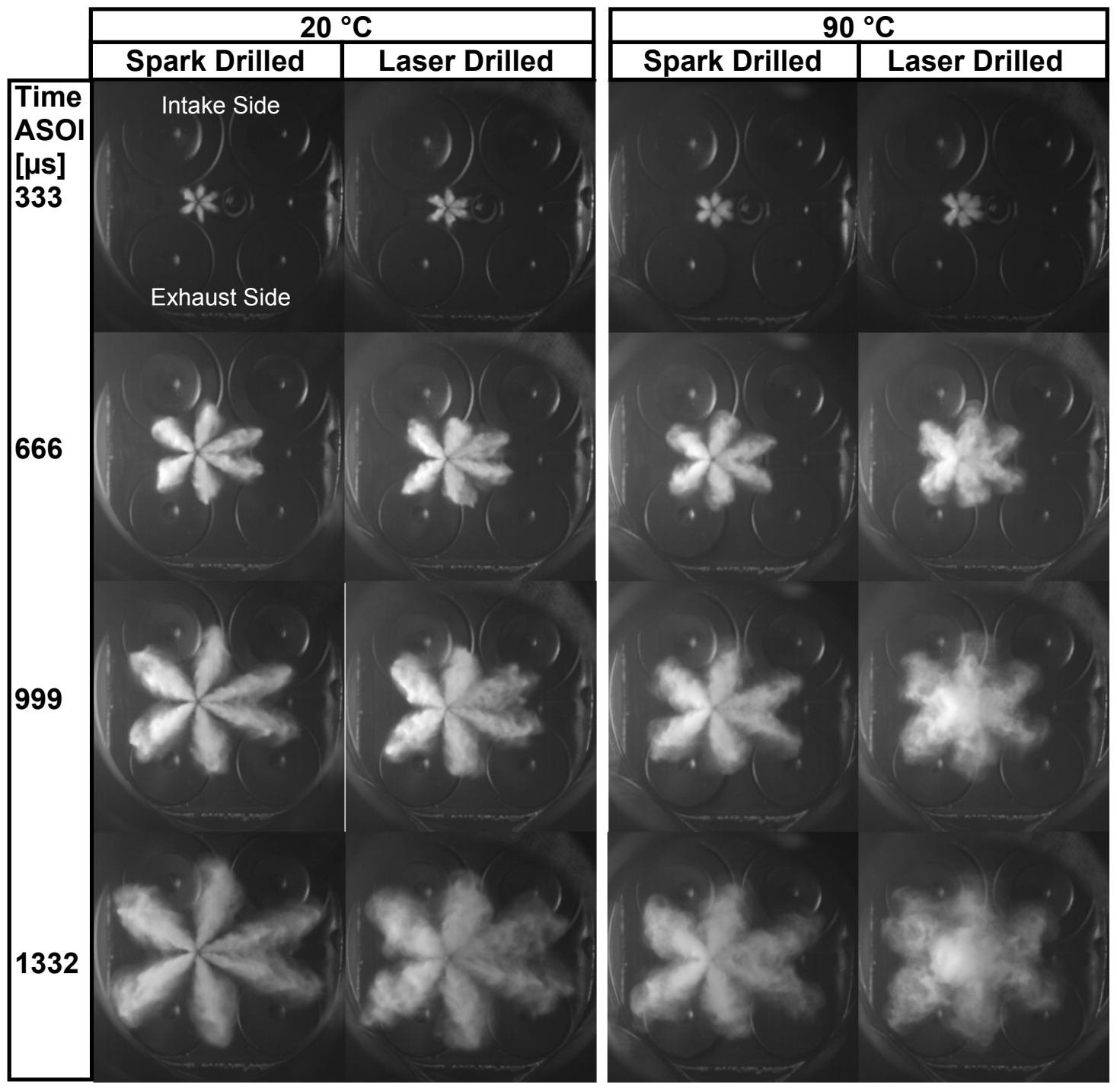




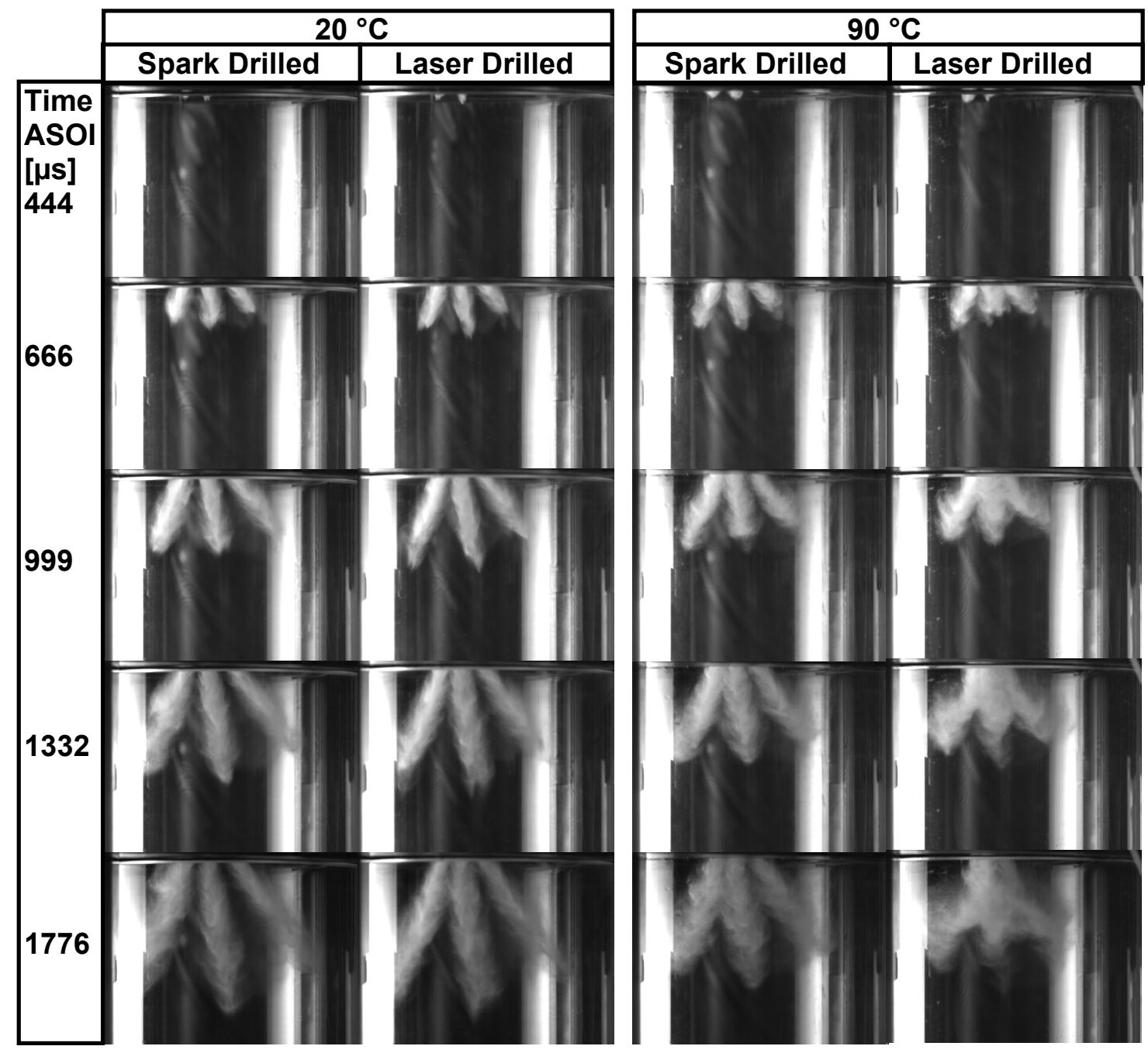

Fig. 11. Instantaneous spray images, exhaust view (0 RPM).
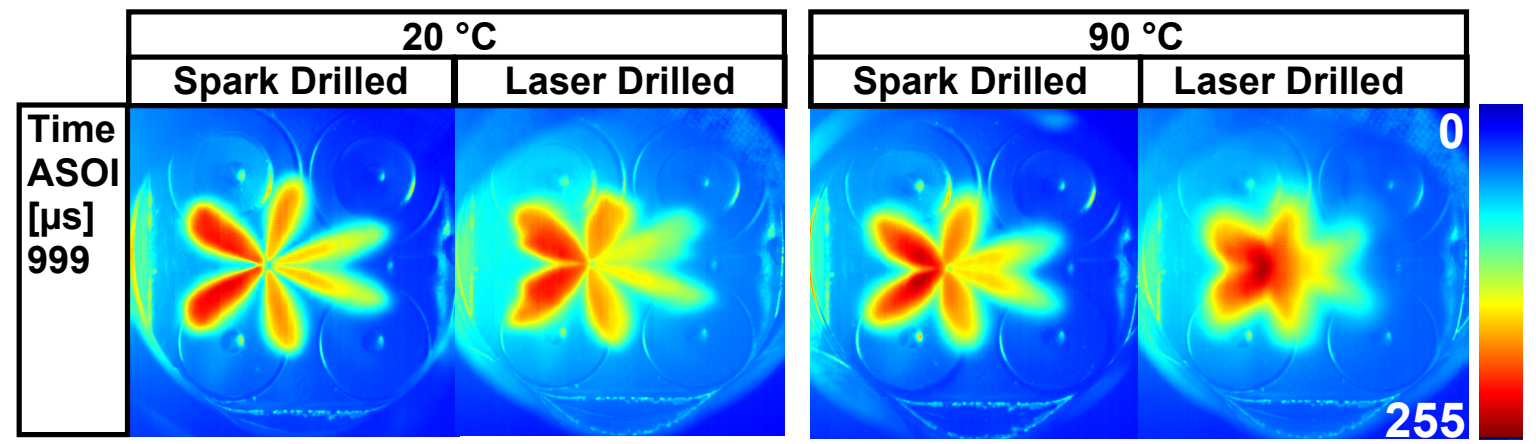

Fig. 12. Mean spray images at 999 us ASOI, piston view (0 RPM). 

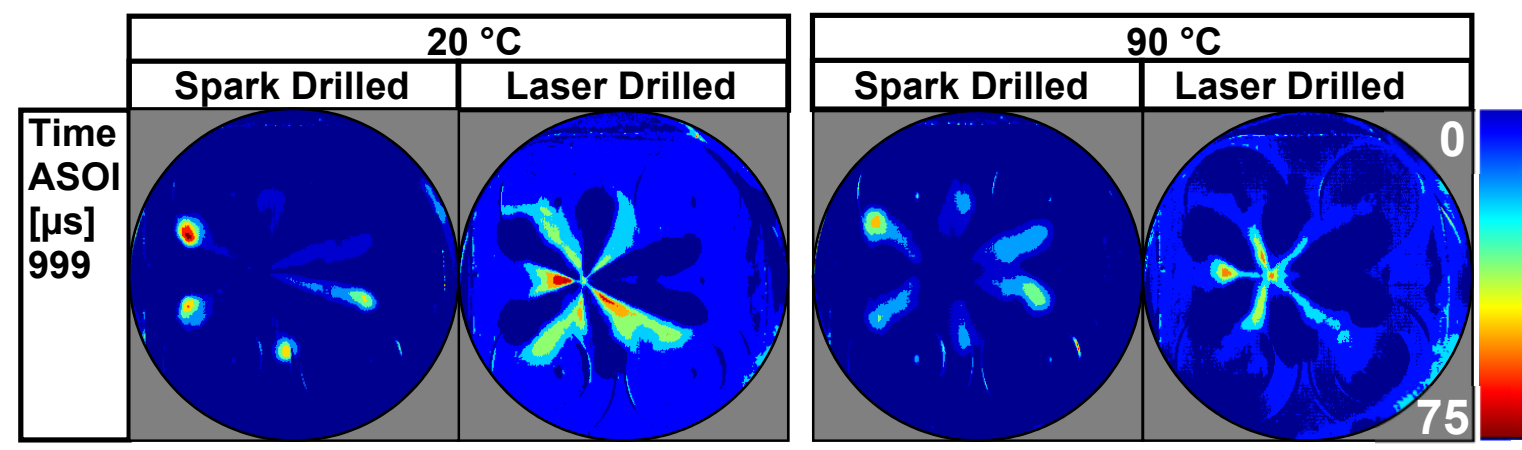

Fig. 13. Mean spray difference (subtraction) images at 999 us ASOI, piston view (0 RPM)
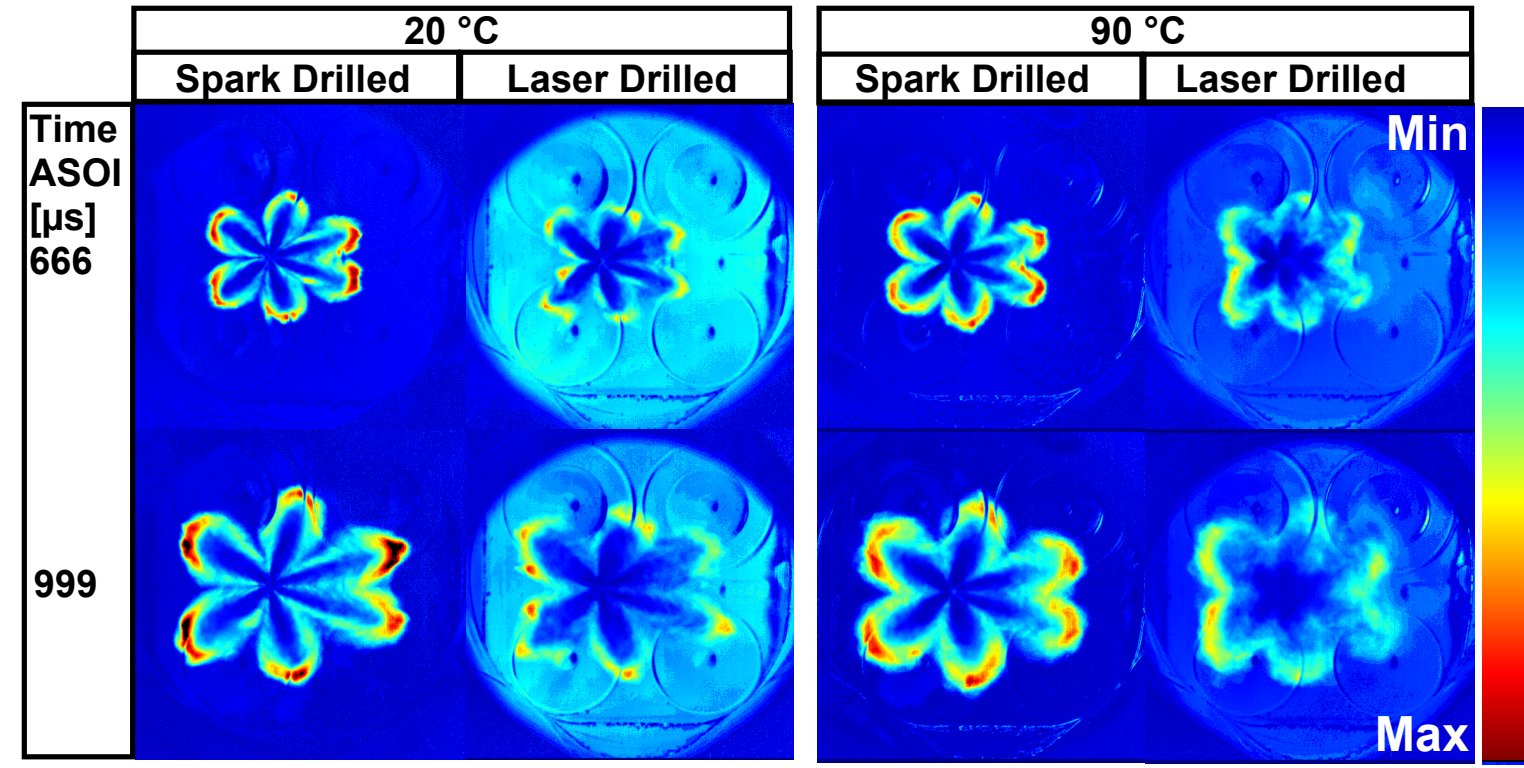

Fig. 14. Coefficient of variation spray images, piston view (0 RPM).
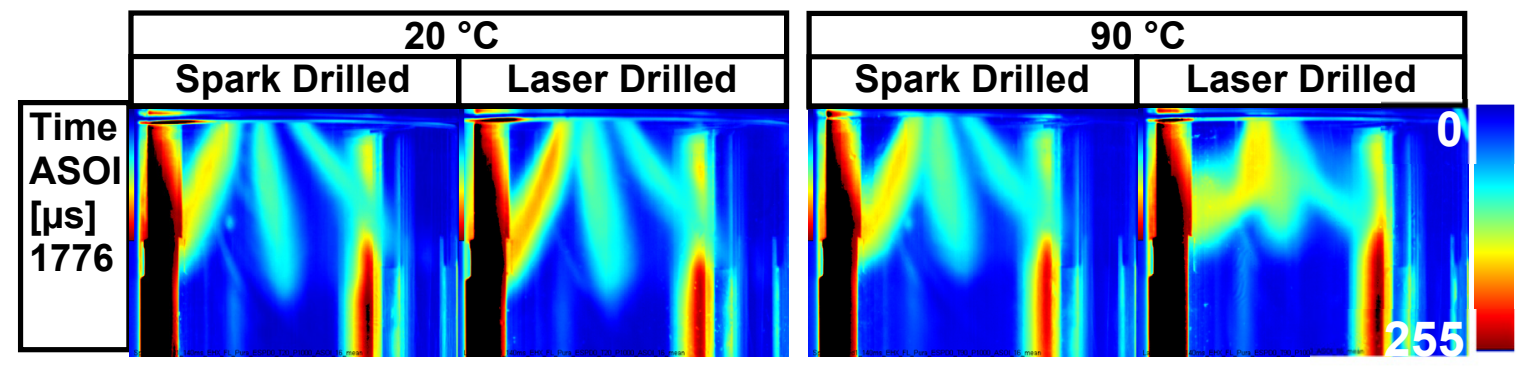

Fig. 15. Mean spray images at $1776 \mu$ s ASOI, exhaust view (0 RPM).
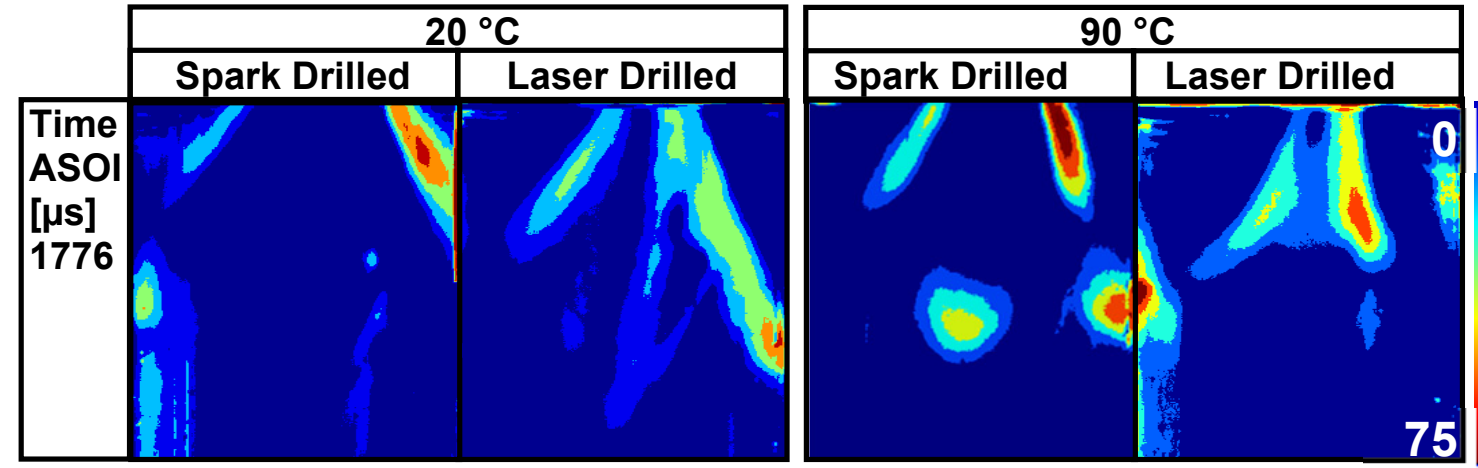

Page 10 of 22

Fig. 16. Mean spray difference (subtraction) images at 1776 us ASOI, exhaust view (0 RPM) 


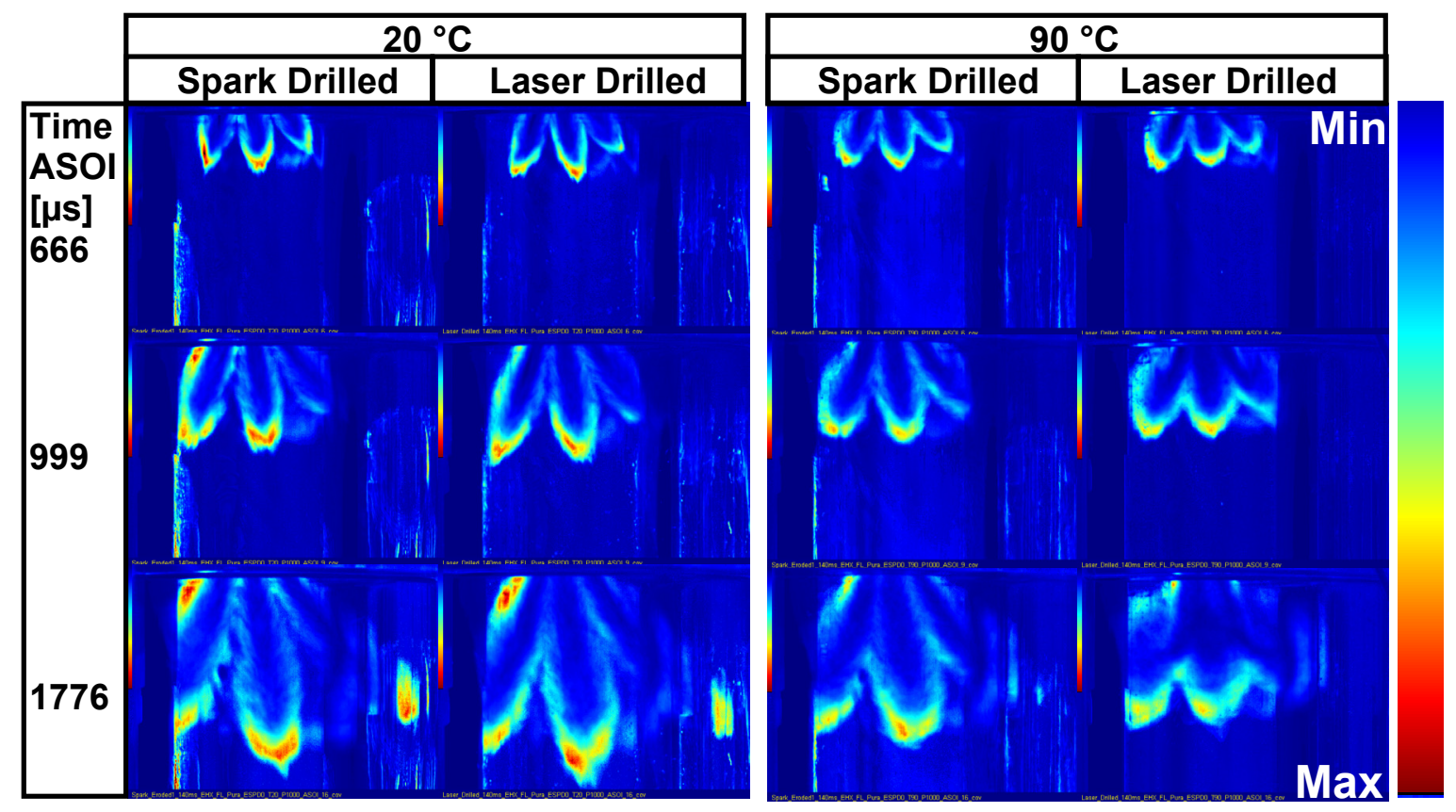

Fig. 17. Coefficient of variation spray images, exhaust view (0 RPM).

\section{Motored Engine Tests}

The results of the injector comparison in the motored engine are shown in Figs. 18-23. The instantaneous, mean and CoV piston view data in Fig. 18, Fig. 20 and Fig. 21 show that the spray was forced towards the cylinder bore/liner on the exhaust side due to the intake air tumble motion. The Laserdrilled injector's spray appeared to be more diffuse, as was seen for the quiescent condition which is highlighted by the greater region of variation in the CoV data of Fig. 21, indicating a larger, more diffuse, spray edge. The instantaneous, mean and CoV exhaust side views in Fig. 19, Fig. 22 and Fig. 23 show that at $20{ }^{\circ} \mathrm{C}$ the spark-drilled and Laser-drilled nozzle sprays were, in general, more similar and there does not appear to be such a marked difference of spray cone angle between the injector types. The mean and CoV images of Fig. 22 and Fig. 23 show that the plumes of the Laser-drilled nozzle, especially those on the left of the image (numbers 3 and 4 of Fig. 1), appear to have increased vertical penetration compared to the spark-drilled nozzle, like that seen for the static engine tests. At $90{ }^{\circ} \mathrm{C}$ the spark-drilled nozzle's spray plumes collapsed towards the injector body axis, which did not happen at quiescent engine conditions. The Laser-drilled nozzle plumes also collapsed, as for quiescent conditions, and to a greater extent than the spark-drilled nozzle plumes. The CoV images of Fig. 23 show that the Laser-drilled nozzle's spray has more variation in a larger spatial region at the plume edges. It can also be seen from Fig. 19, Fig. 22 and Fig. 23 that the Laser-drilled nozzle's spray impinges the piston earlier than the spark-drilled nozzle's spray, especially at $90{ }^{\circ} \mathrm{C}$ where the Laser-drilled nozzle's spray collapses to a greater extent than the spark-drilled nozzle's spray.

It is important to highlight the key differences of spray behaviour between quiescent and motored conditions; at $90{ }^{\circ} \mathrm{C}$ the spark-drilled nozzle's spray did not collapse for quiescent conditions but did collapse for the motored conditions and the Laser-drilled nozzle's spray collapsed for both quiescent and motored conditions. The effect of the collapsed spray on vertical spray penetration was also different and dependent on the presence of intake airflow. For quiescent conditions the collapsed spray of the Laser-drilled nozzle showed reduced penetration compared to the spark-drilled nozzles noncollapsed spray due to increased plume interaction and evaporation. However, for motored conditions the spray collapse had the effect of increasing vertical spray penetration which was most for the more collapsed Laser-drilled nozzle's spray. These changes of penetration characteristic between quiescent and motored conditions can be attributed to the effect of intake airflow on the collapsed spray; the increased vertical velocity component of the collapsed spray, combined with the large vertical component of the intake tumble airflow rapidly transports the spray towards the piston crown, particularly for the more collapsed Laser-drilled nozzle's spray. This key difference of the presence spray collapse and its effect on vertical penetration between quiescent and motored engine conditions is important to note because injectors are often specified in a quiescent environment and effects of intake airflow may not always be properly considered. 


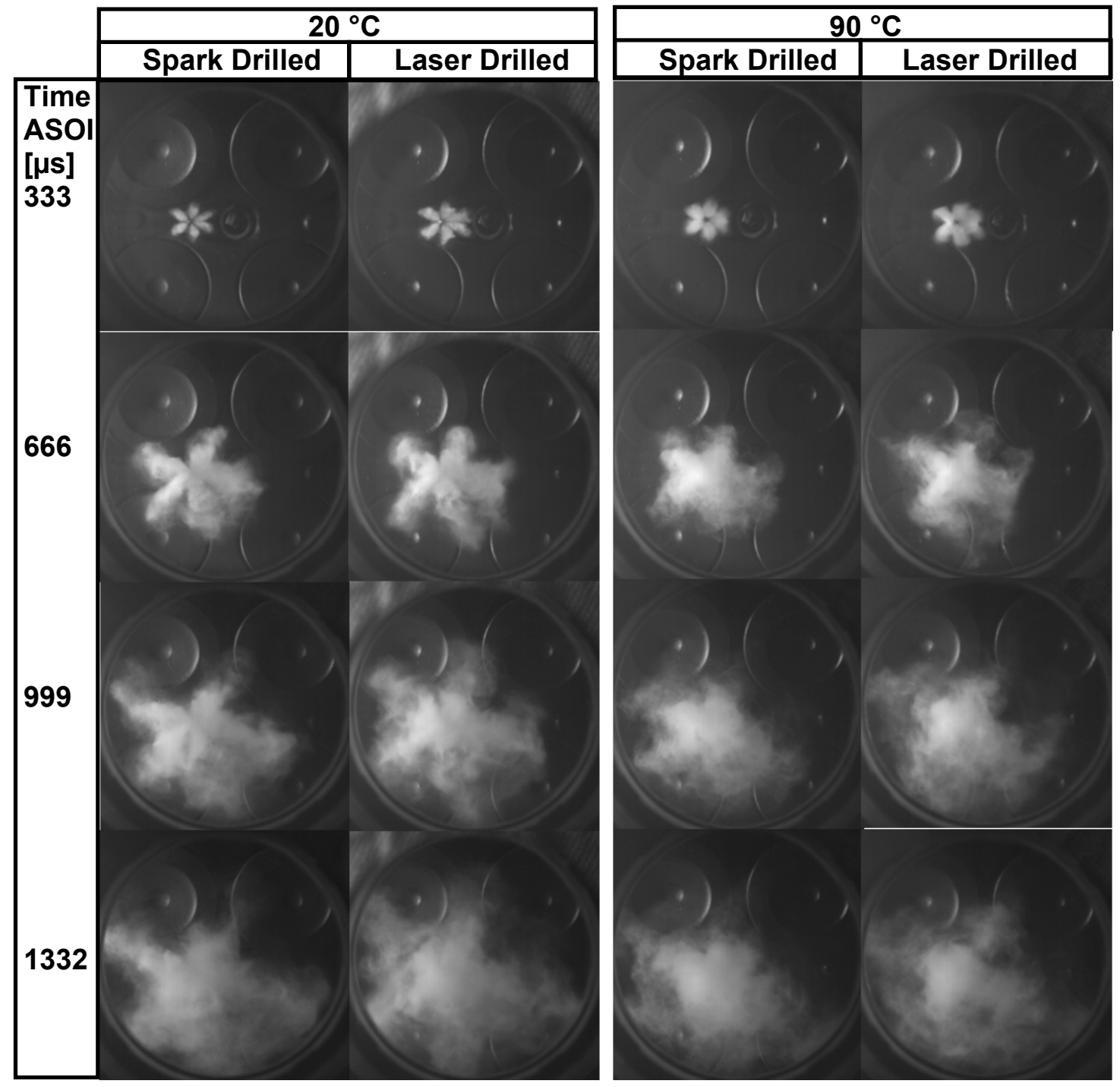

Fig. 18. Instantaneous spray images; SOI= $290^{\circ} \mathrm{BTDC}$, piston view $\left(1750 \mathrm{RPM}, 1^{\circ} \mathrm{CA}=95.24 \mu \mathrm{s}\right)$ 


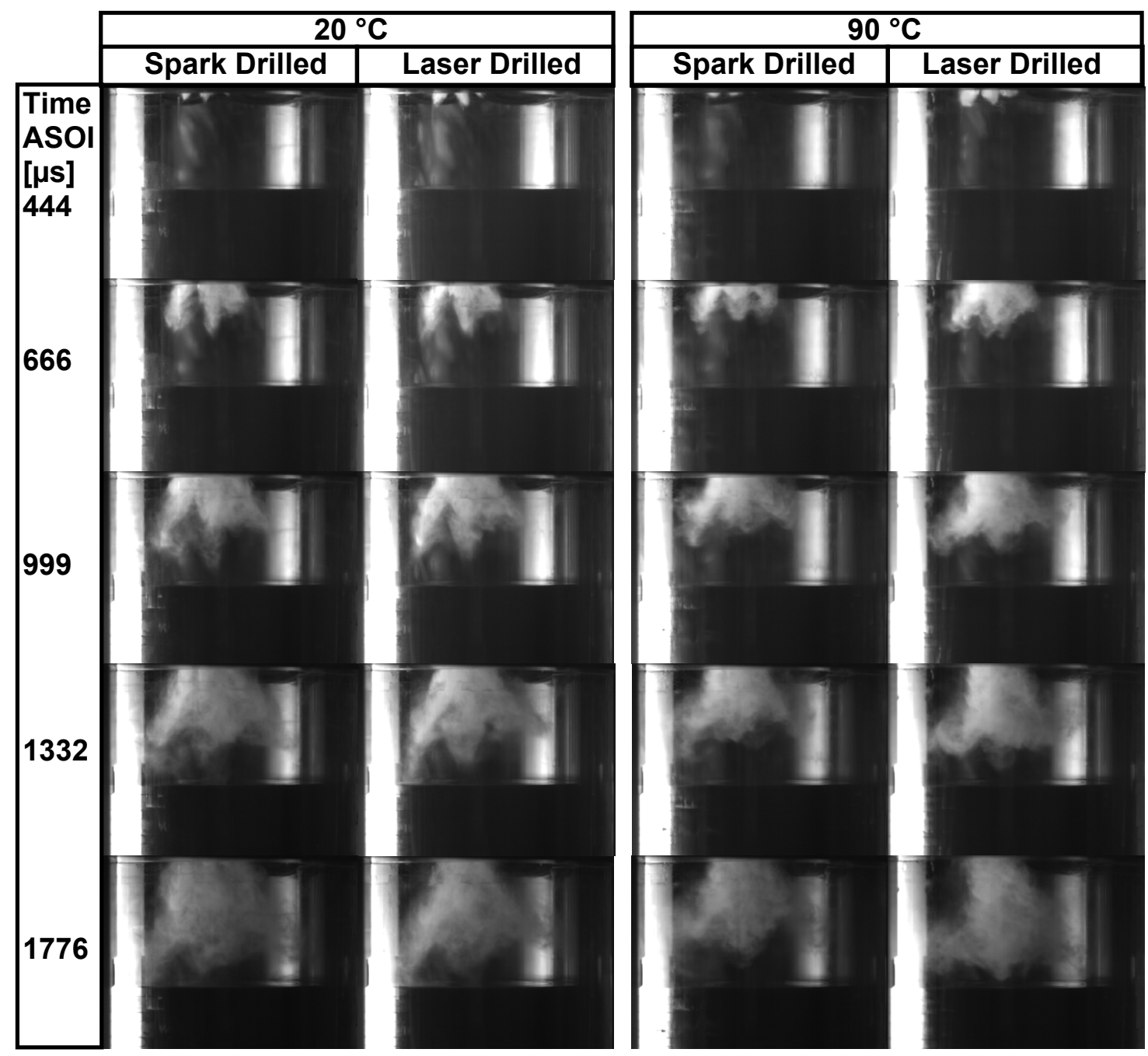

Fig. 19. Instantaneous spray images; SOI $=290^{\circ} \mathrm{CA} B T D C$, exhaust view $\left(1750 \mathrm{RPM}, 1^{\circ} \mathrm{CA}=95.24 \mu \mathrm{s}\right)$.
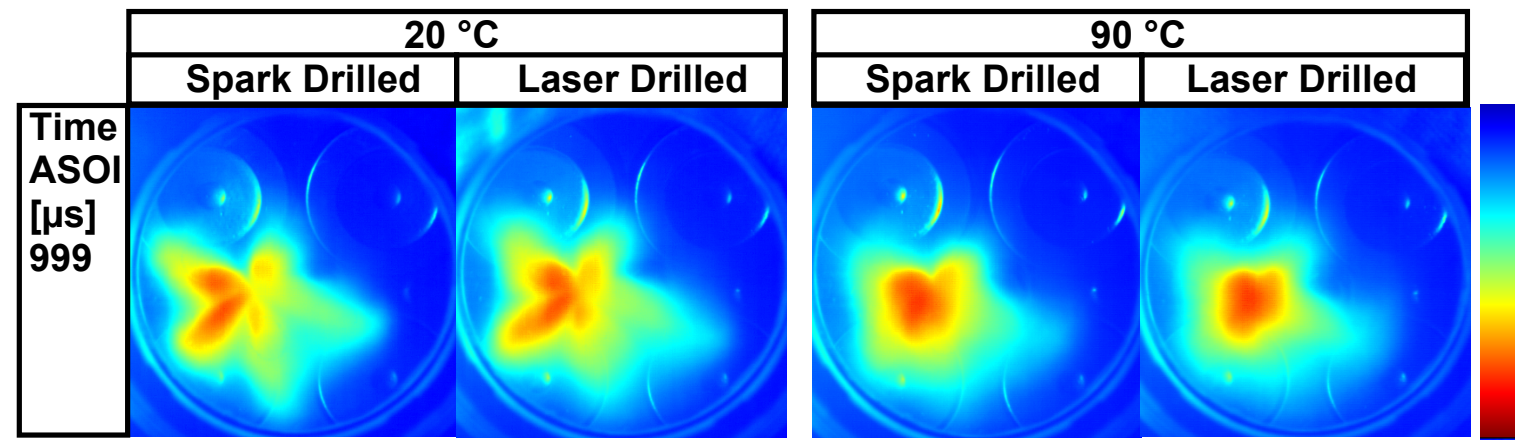

Fig. 20. Mean spray images at $999 \mu \mathrm{s} A S O$, piston view (1750 RPM, $\left.1^{\circ} \mathrm{CA}=95.24 \mu \mathrm{s}\right)$. 

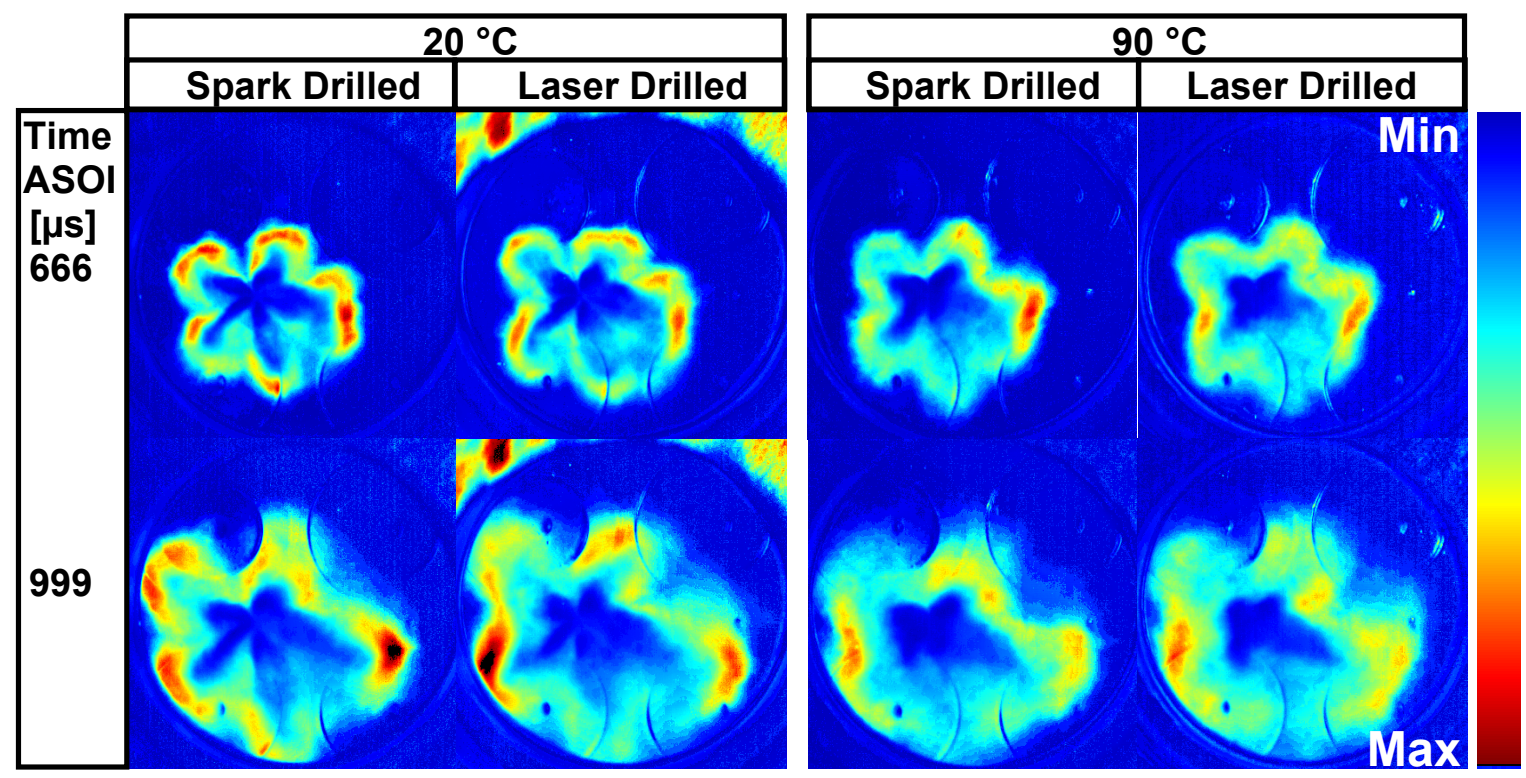

Fig. 21. Coefficient of variation spray images, piston view (1750 RPM, $1^{\circ} \mathrm{CA}=95.24 \mu \mathrm{s}$ ).
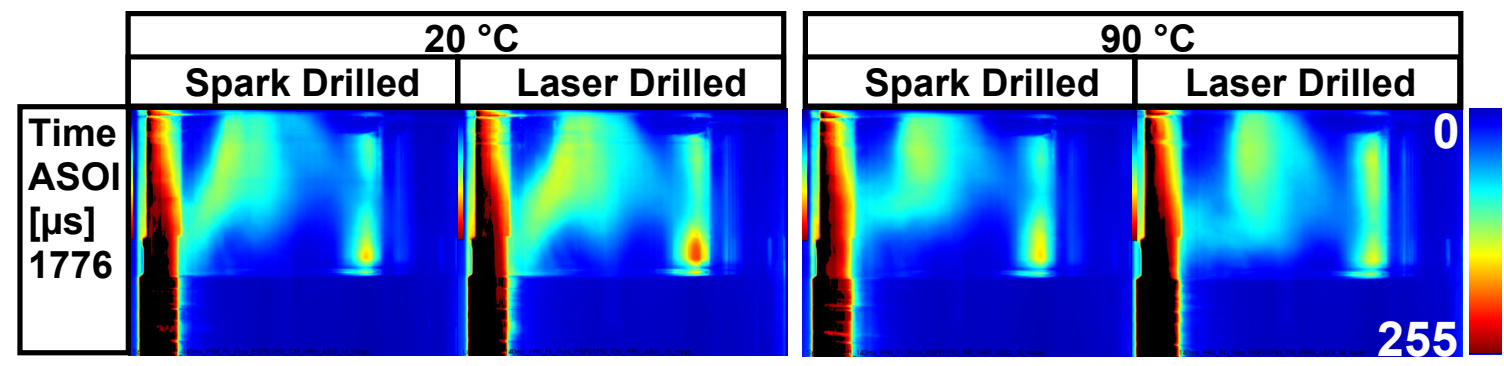

Fig. 22. Mean spray images at $1776 \mu \mathrm{s}$ ASOI, exhaust view (1750 RPM, $\left.1^{\circ} \mathrm{CA}=95.24 \mu \mathrm{s}\right)$.
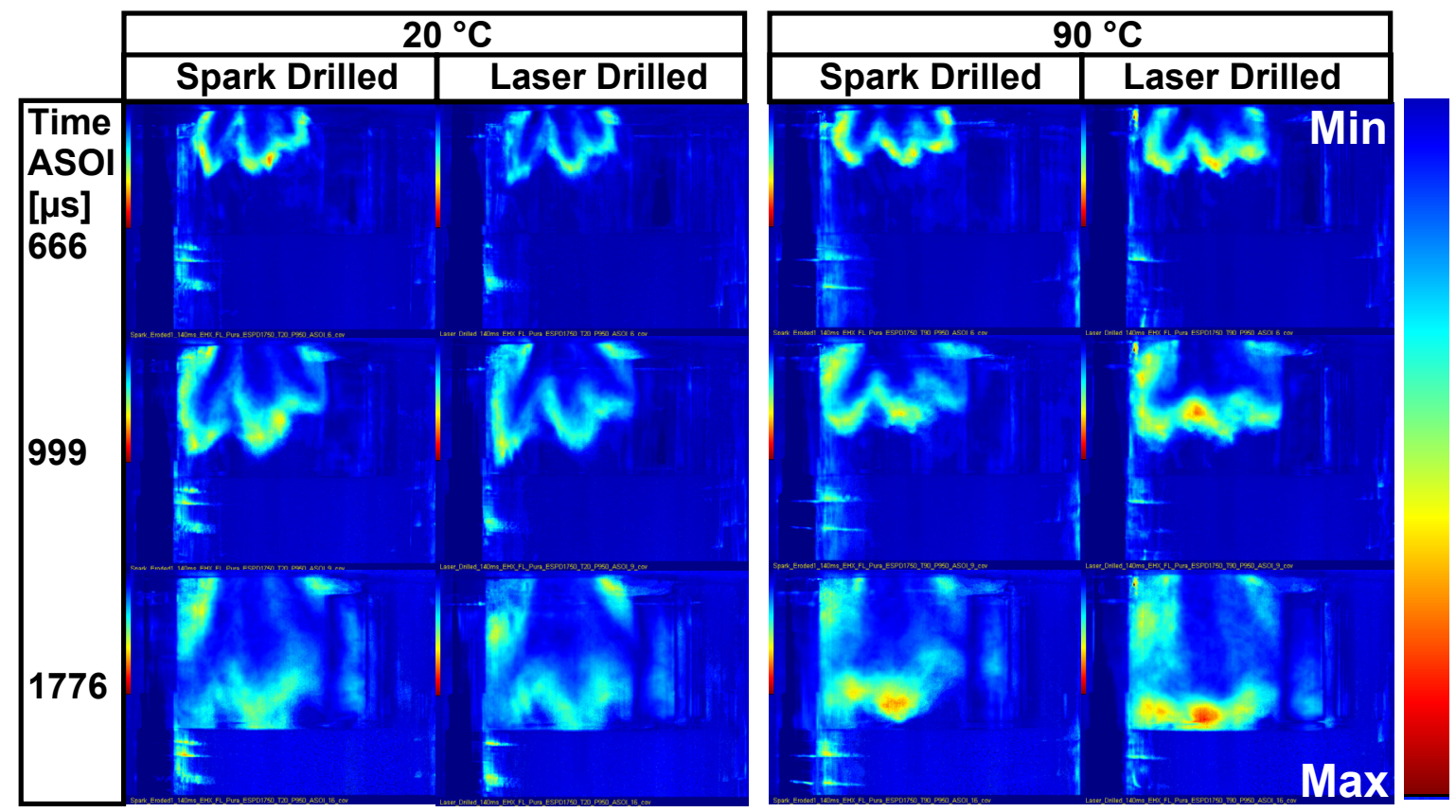

Fig. 23. Coefficient of variation spray images, $\mathrm{SOI}=290^{\circ} \mathrm{CA} B T D C$, exhaust view $\left(1750 \mathrm{RPM}, 1^{\circ} \mathrm{CA}=95.24 \mu \mathrm{s}\right)$. 


\section{Spray Penetration and Cone Angle}

To further investigate and quantify the differences of the spray's vertical penetration and cone angles, the data were further processed and the results of each injector type compared. The angle of the left plumes (pair 3 and 4 shown in Fig. 1) relative to the vertical was used for the cone angle analysis and as such the values derived are half-cone angles. The spray half-cone angle was calculated on a frame-by-frame basis over the duration of injection and was defined as the angle formed from the injector tip to the edge of the left plumes at a vertical distance of $20 \mathrm{~mm}$ (motored tests) and $25 \mathrm{~mm}$ (static tests) from the injector tip. A schematic defining the spray's half-cone angle is shown in Fig. 24 (sprays shown at $1.32 \mathrm{~ms}$ ASOI for static engine). Each image batch required a 'virtual pegging' process to define the injector location relative to the image. Fig. 24 also shows the definition of the vertical penetration distance from the injector's tip.

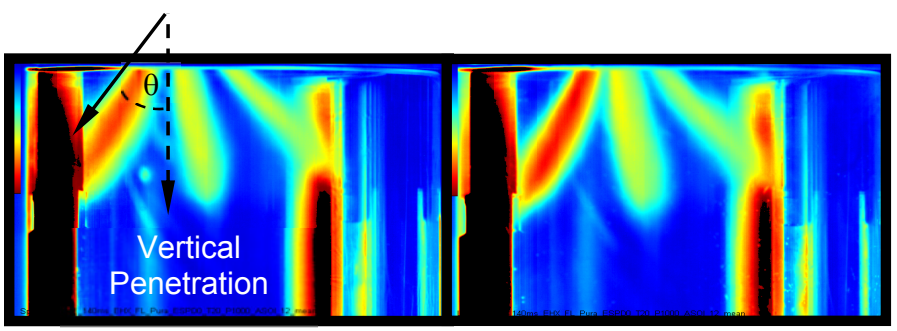

Fig. 24. Spray half-cone angle definition $(\theta)$; spark-drilled (left) and Laser-drilled (right) injector, $1.32 \mathrm{~ms} \mathrm{ASOI.}$

Thresholds of light level were applied to the mean spray data and binary images were created which represented regions of spray/no spray, and were subsequently processed to reveal quantitative differences of vertical penetration and half-cone angle between the two injector types. The nature of the flash lamp's decreasing light intensity as the spray event proceeds necessitated threshold level selection on a frame-by-frame basis which was achieved by selecting a threshold level based on a percentage of the respective maximum intensity for each frame, thereby normalising the analysis and accounting for differences of light intensity between the tests. Selecting a high threshold percentage has the effect of removing the outer edges of the spray from the images, where the light intensity was lower, and so shows only the dense bright spray plume cores. Decreasing the threshold includes more of the spray's edge but there was a limit to the threshold reduction, where the effectiveness of the analysis was hindered by the signal-tonoise ratio. Analysis of various levels of threshold showed that a value of $15 \%$ of the maximum intensity of each frame was the most appropriate, below which noise was a limiting factor.

Spray penetration results of the two injector types are shown in Fig. 25 and Fig. 27 and spray half-cone angle comparison is shown in Fig. 26 and Fig. 28. The spray penetration in the static engine in Fig. 25 shows that there was not much penetration difference between the injectors at $20^{\circ} \mathrm{C}$, however there were significant differences at $90{ }^{\circ} \mathrm{C}$. At $20^{\circ} \mathrm{C}$ the Laserdrilled nozzle had increased penetration by $2-3 \mathrm{~mm}$ compared to the spark-drilled nozzle but the difference disappeared after approximately $80 \mathrm{~mm}$ of spray penetration. This initial penetration difference may be due to variation of individual nozzle-hole angles between the injector types. At $90{ }^{\circ} \mathrm{C}$ a marked difference between the two nozzle types was seen and the Laser-drilled nozzle's spray penetration was much less (up to $12 \mathrm{~mm}$ ) than the spark-drilled type due to the Laser-drilled nozzle's spray collapse towards the injector body axis and the increased plume interaction and vaporisation. Although there was a greater vertical velocity component for the collapsed spray, it appears this was offset by the spray's greater momentum exchange with the ambient air which reduced the vertical penetration compared to the spark-drilled.

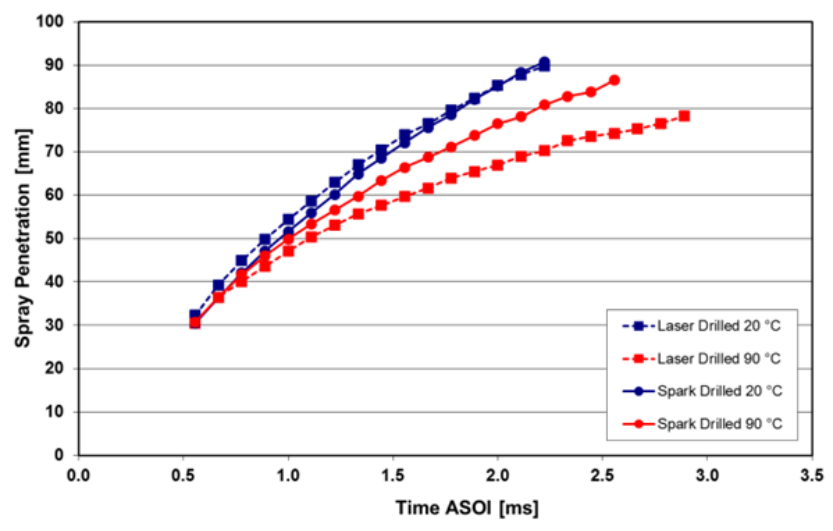

Fig. 25. Vertical spray penetration static engine tests.

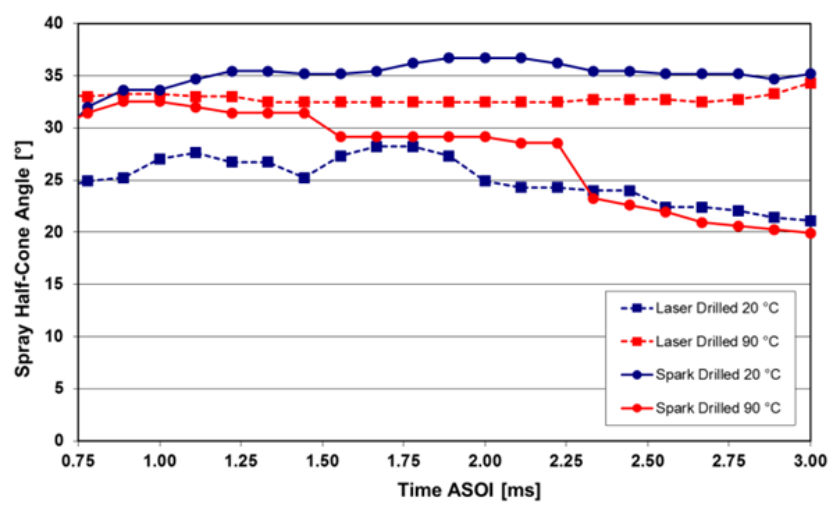

Fig. 26. Spray half-cone angle, static engine.

It can be seen in the static engine data of Fig. 26 that at $20^{\circ} \mathrm{C}$ the Laser-drilled nozzle had a more acute spray half-cone angle by a margin of over $10^{\circ}$ at times, compared to the sparkdrilled nozzle which may be due to differences of drilling angles of the individual injector holes. Fig. 26 shows that the spray half-cone angle was smaller for the Laser-drilled injector at 20 ${ }^{\circ} \mathrm{C}$, however the opposite trend was true at $90{ }^{\circ} \mathrm{C}$ and shows the Laser-drilled injector angle to be larger. Fig. 26 at $90{ }^{\circ} \mathrm{C}$ indicates a more acute half-cone angle for the non-collapsed spark-drilled injector spray, however this can be misleading if not put into context as the Laser-drilled injector underwent spray collapse which led to a more acute spray half-cone angle. The reason for this observation is that the Laser-drilled nozzle's collapsed spray exhibited re-circulation patterns on its periphery in the region where the angle measurement was based. Although strictly the angle values are correct by definition it can be seen from the instantaneous, mean and CoV images of Fig. 11, Fig. 15 and Fig. 17 that the dense collapsed spray core was much more acute than that of the spark-drilled nozzle at $90{ }^{\circ} \mathrm{C}$. 
The spray penetration and half-cone angle comparison for the injectors in the motored engine are shown in Fig. 27 and Fig. 28 , respectively. It can be seen in Fig. 27 that at $20^{\circ} \mathrm{C}$ the Laser-drilled nozzle had increased vertical spray penetration, typically between $2-4 \mathrm{~mm}$, and impinges the piston $2-3^{\circ} \mathrm{CA}$ earlier (at 1750 RPM) compared to the spark-drilled nozzle and perhaps could be due to differences of drilling angle of the individual nozzle hole's. Fig. 27 shows greater penetration for the Laser-drilled injector at $90{ }^{\circ} \mathrm{C}$ which was the opposite trend to that seen at static conditions, where it had smaller (Fig. 25). Although at $90{ }^{\circ} \mathrm{C}$ the Laser-drilled nozzle's penetration was initially lower than that seen for both injector types at $20^{\circ} \mathrm{C}$, the penetration of the more collapsed Laser-drilled nozzle later increases to above the $20{ }^{\circ} \mathrm{C}$ spark-drilled nozzle's after 55 $\mathrm{mm}$ and to marginally above the $20^{\circ} \mathrm{C}$ Laser-drilled nozzle's after $65 \mathrm{~mm}$, to have the greatest overall penetration. It is reiterated that this behaviour was different to that seen in quiescent conditions where without the intake air tumble flow the Laser-drilled nozzle's collapsed spray at $90{ }^{\circ} \mathrm{C}$ had the least penetration of the tests. This is likely to be due to the increased vertical velocity component of the collapsed spray being further increased by the large vertical velocity component of the intake air tumble motion. At $90{ }^{\circ} \mathrm{C}$ the Laserdrilled nozzle had an increased level of spray collapse (Fig. 28) leading to greater vertical spray penetration than the sparkdrilled, by 4-5 $\mathrm{mm}$ early on and later up to $9 \mathrm{~mm}$ as the spray approaches the piston. The Laser-drilled nozzle's spray impinges on the piston the earliest, typically $3-4^{\circ} \mathrm{CA}$ earlier (at 1750 RPM) than the spark-drilled nozzle's spray at $90^{\circ} \mathrm{C}$.

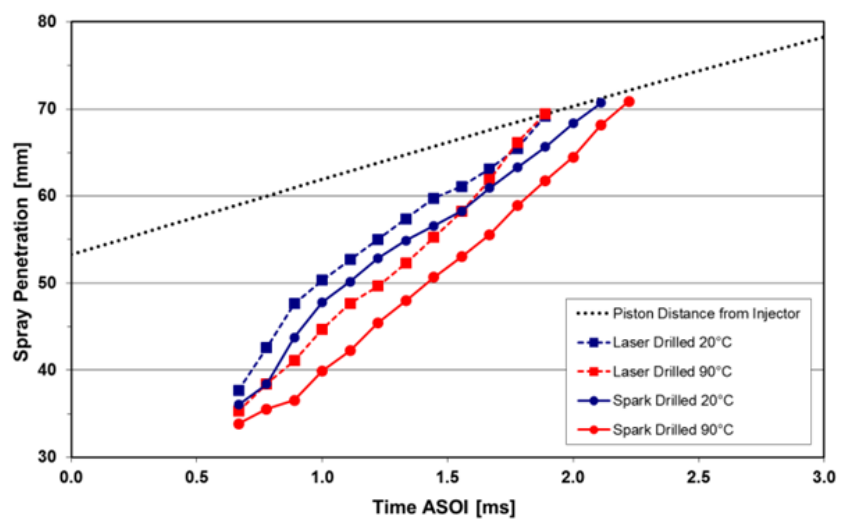

Fig. 27. Vertical spray penetration, motored engine (1750 RPM).

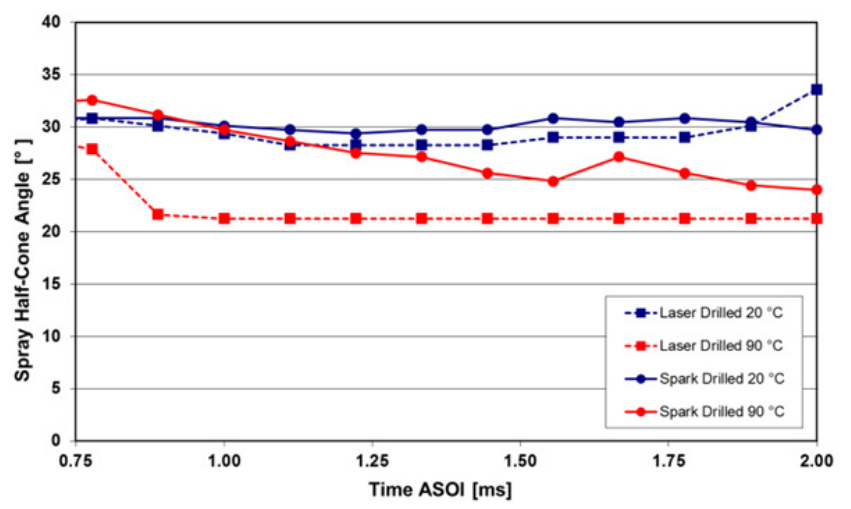

Fig. 28. Spray half-cone angle, motored engine (1750 RPM).
The Laser-drilled nozzle's higher level of spray collapse is shown in Fig. 28 where it can be seen that it has the most acute spray angle and was almost $10^{\circ}$ more acute, at times, than the spark-drilled nozzle. At $20{ }^{\circ} \mathrm{C}$ differences of spray half-cone angle between the injectors were not as marked as that seen for quiescent conditions although it can be seen from Fig. 28 that the Laser-drilled nozzle has a marginally more acute angle. The effect of the intake tumble airflow appears to reduce the half-cone angle difference between the injector types at $20{ }^{\circ} \mathrm{C}$. The stronger degree of spray collapse of the Laser-drilled nozzle may be linked to the interaction of the wider more diffused spray with the surrounding air and associated entrainment effects, whereby a lower gas pressure region is formed towards the central core of the spray than in the case of the spark-drilled one.

\section{Spray Droplet Sizing}

Example of measured scatter plots of droplet size and velocity are shown in Fig. 29 and Fig. 30, respectively. These correspond to the spark-drilled injector at position 15, i.e. in the outside region of the spray plume. A moving average line has also been superimposed on those scatter plots for clarity. The data shown comprise 200 full injection events at $20^{\circ} \mathrm{C}, 0.5$ bar pressure. It can be seen that data within the initial period of injection $(<1 \mathrm{~ms})$ which contains the tip of the spray plume, features the largest and highest velocity droplets.

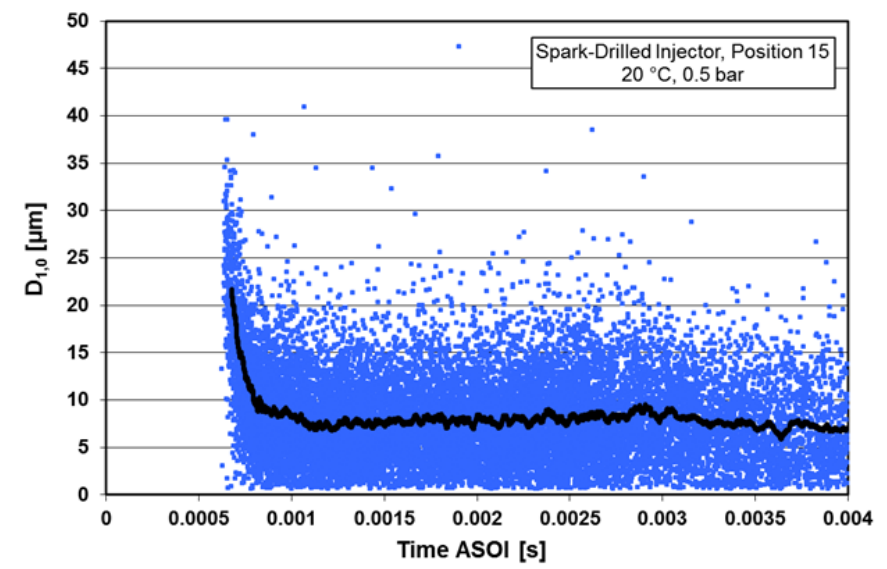

Fig. 29. Typical PDA droplet size scatter plot with moving average.

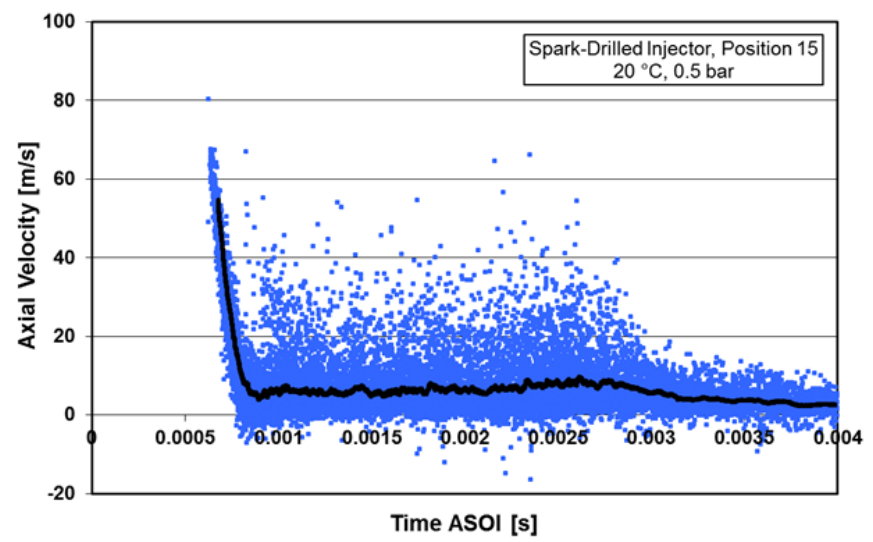

Fig. 30. Typical PDA droplet velocity scatter plot with moving average.

Page 16 of 22 
Fig. 31 shows the overall droplet size histograms containing data across all measurement positions where it can be seen that the Laser and spark-drilled results show very similar size distributions at the temperature and pressures tested. A maximum droplet size cut-off of $40 \mu \mathrm{m}$ was selected by scrutinizing the histogram data of Fig. 31. Sizes above $40 \mu \mathrm{m}$ were not included in the calculations of average droplet size as it is known inclusion of just a few large droplets can have a significant influence on the volume-to-surface area ratio Sauter Mean Diameter (SMD, $\left.D_{3,2}\right)$ calculation.
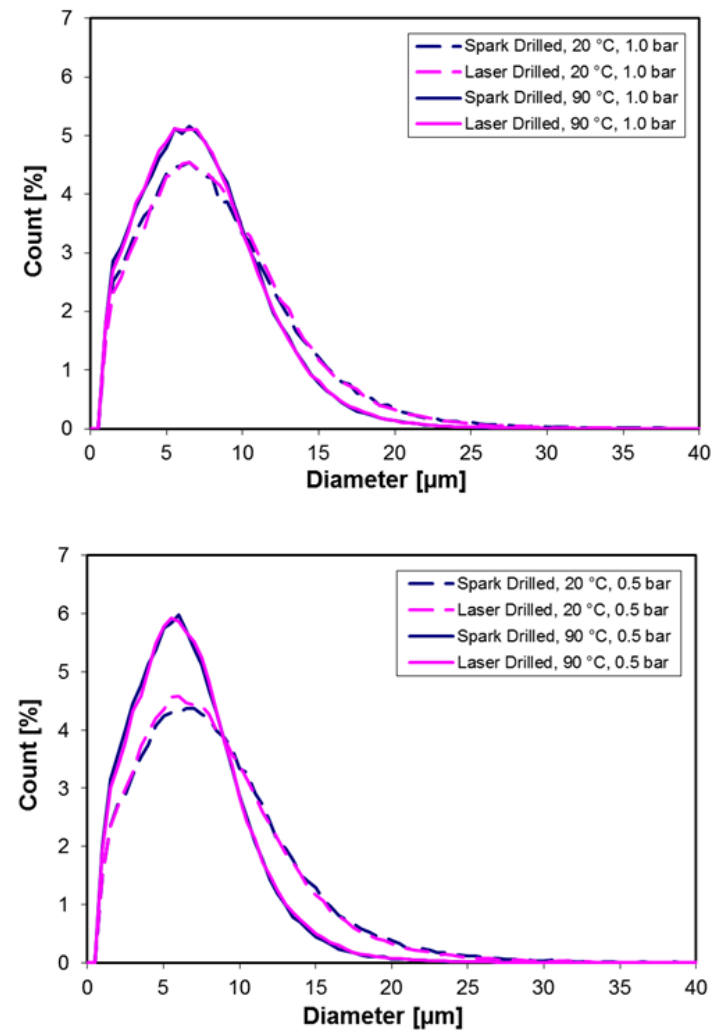

Fig. 31. Droplet size histograms over 4 ms ASOI.

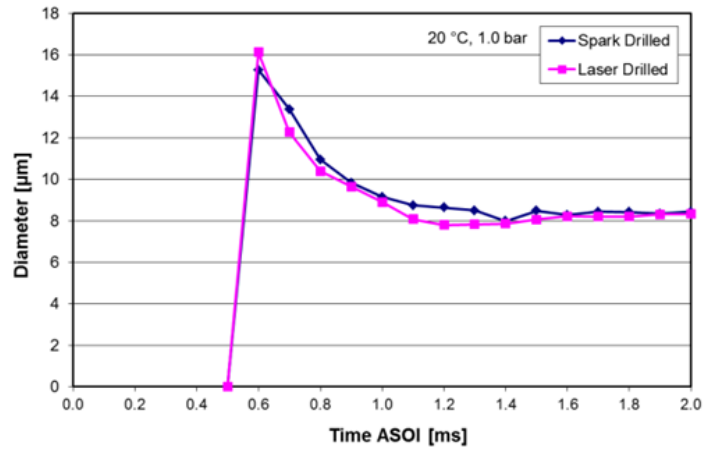

Fig. 32. Droplet size variation over time, $20^{\circ} \mathrm{C}, 1.0$ bar.

In addition to the entire $4 \mathrm{~ms}$ measurement period per injection, droplet size data were also evaluated separately for just the early period of injection. This early period contains information on spray plume tip phenomena where the droplet sizes and velocities were measured to be the greatest, hence it can provide information on initial breakup mechanisms with the Page 17 of 22 two injectors under study. To determine an appropriate length for this important early spray period, the average droplet size (arithmetic mean, $D_{1,0}$ ) was first plotted against time, as shown in Fig. 32. It can be seen that the initially large $D_{1,0}$ values reduce greatly within the first $1 \mathrm{~ms} A S O I$ and remain relatively stable after that. Therefore, it was decided to evaluate and compare data separately for the $1 \mathrm{~ms}$ and $4 \mathrm{~ms}$ ASOI periods. Inevitably the $1 \mathrm{~ms}$ time period results contained a much lower number of validated measured droplets which must be borne in mind. It can also be seen in Fig. 32 that droplets were only present for about $0.3 \mathrm{~ms}$ of the first $1 \mathrm{~ms}$, owing to the injector driver's and needle opening delay. This delay has been quantified in detail in earlier publications, e.g. see [10].

The results in Figs. 33-40 show SMD $\left(D_{3,2}\right)$ droplet size results at different positions from the inside across to the outside of a single spray plume. Position numbers are multiples of $1.27 \mathrm{~mm}$ from injector body axis and it is noted that a $40 \mu \mathrm{m}$ max size cut-off has been applied as explained earlier. It can be seen in Fig. 33 that at $20{ }^{\circ} \mathrm{C}, 1.0$ bar downstream pressure the smallest SMD droplet sizes for both injector types were seen at the lower position numbers corresponding to the inside region of the spray plume, closest to the injector body axis. The SMD values were larger at higher position numbers, corresponding to the outer regions of the spray plume, especially for the spark-drilled injector where the SMD values were greater than in the centre region of the spray. The largest SMD droplet size overall, $15.4 \mu \mathrm{m}$, was found in the centre to outside region of the spark-drilled injector at position 11, and the smallest size, $11.7 \mu \mathrm{m}$, was found for the spark-drilled nozzle at the inner spray plume region at position 4 and was marginally smaller than the Laser-drilled case at the same position.

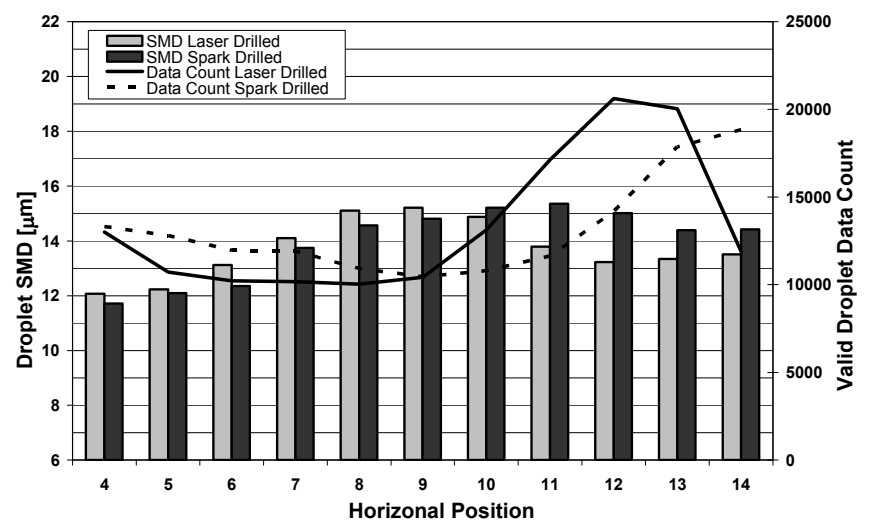

Fig. 33. Droplet SMD, $20^{\circ} \mathrm{C}, 1.0$ bar; averaged over $4 \mathrm{~ms}$ ASOI.

The differences of SMD droplet size between the spark and Laser-drilled nozzles were greatest at the outside region of spray (positions 10 to 14) furthest from the injector body axis i.e. closest to the cylinder bore. In this outside region of the spray plume it can be seen that the Laser-drilled nozzle has significantly smaller SMD values, especially at positions 11 and 12 where they were approximately $1.6 \mu \mathrm{m}$ and $1.8 \mu \mathrm{m}$ smaller, respectively, than the spark-drilled nozzle SMD droplet sizes. However, the opposite trend of droplet size difference between the injector types was seen at the inside to centre region of the spray plume, (positions 4 to 9) where the Laser-drilled nozzle's SMDs were larger than the spark-drilled nozzle's - although the difference was not as great as seen at the higher position numbers, towards the outside of the spray plume. 
Fig. 34 shows SMD values across the spray during the first 1 ms ASOI. These early values were much larger than when averaged over $4 \mathrm{~ms}$ and the trends of difference between the injector types at the inner and outer spray region were even more prominent than seen for the $4 \mathrm{~ms}$ period. The Laserdrilled injector's SMD was up to $3.3 \mu \mathrm{m}$ larger at the inside of the spray at position 6 and up to $2.8 \mu \mathrm{m}$ smaller at the outside of the spray at position 13 .

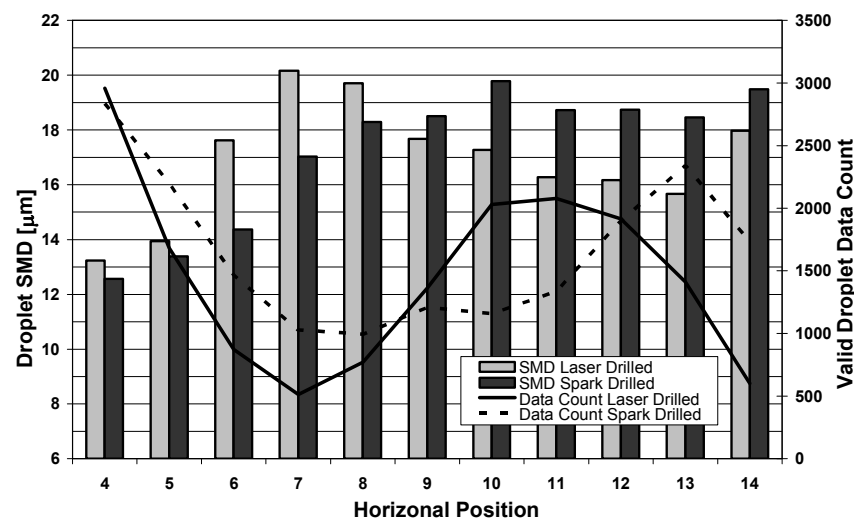

Fig. 34. Droplet SMD, $20^{\circ} \mathrm{C}, 1.0$ bar, averaged over first $1 \mathrm{~ms}$ ASOI.

Fig. 35 shows that at $20^{\circ} \mathrm{C}, 0.5$ bar, a similar trend of injector type differences to those observed at $20^{\circ} \mathrm{C}, 1.0$ bar in Fig. 33 . At positions 4 to 7 , at the inside to centre region of the spray plume, the Laser-drilled nozzle had larger SMD values than the spark-drilled nozzle, up to approximately $1.3 \mu \mathrm{m}$ larger. Positions 9 to 15, between the centre and outside region of the spray plume show that the Laser-drilled nozzle had smaller SMD values than the spark-drilled nozzle, up to approximately $1.6 \mu \mathrm{m}$ smaller seen at position 13. The largest SMD value was found for the Laser-drilled injector at position 6; this was $15.3 \mu \mathrm{m}$. The smallest SMD value was $12.5 \mu \mathrm{m}$ from the Laser-drilled nozzle at position 14.

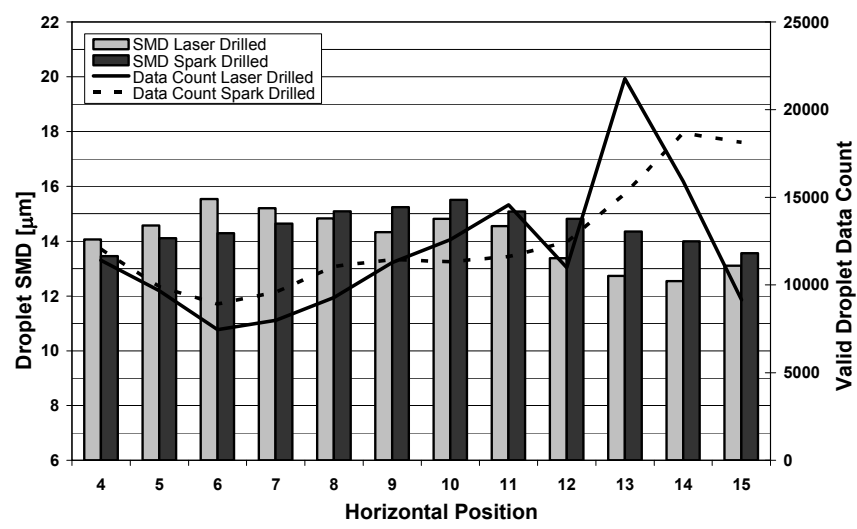

Fig. 35. Droplet SMD, $20^{\circ} \mathrm{C}, 0.5$ bar, averaged $4 \mathrm{~ms}$ ASOI.

Fig. 35 shows similar SMD values in general to those seen at 1.0 bar downstream pressure in Fig. 33. However, large differences were seen at the inside region of the spray plume, at positions 4 to 7 for the 0.5 bar downstream pressure (Fig. 35), where the SMD values were much larger than those at similar positions for the 1.0 bar downstream pressure case (Fig. 33). For the $20^{\circ} \mathrm{C}, 0.5$ bar case of Fig. 35 the smallest
SMD was found on the outside of the spray plume but in the 20 ${ }^{\circ} \mathrm{C}, 1.0$ bar case of Fig. 33 the smallest SMD was on the inside of the spray plume. The results of $20^{\circ} \mathrm{C}, 0.5$ bar during the first $1 \mathrm{~ms}$ ASO shown in Fig. 36 indicate the largest SMD values of all the conditions tested in this work. At position 7 the SMD of the Laser-drilled injector reaches $21.1 \mu \mathrm{m}, 1.9 \mu \mathrm{m}$ larger than the spark-drilled injector. The Laser-drilled spray's droplets were smaller by up to $3.3 \mu \mathrm{m}$, at position 13 in the outside region of the spray. The smallest SMDs are found at position 4, down to $13.4 \mu \mathrm{m}$ for the spark-drilled injector.

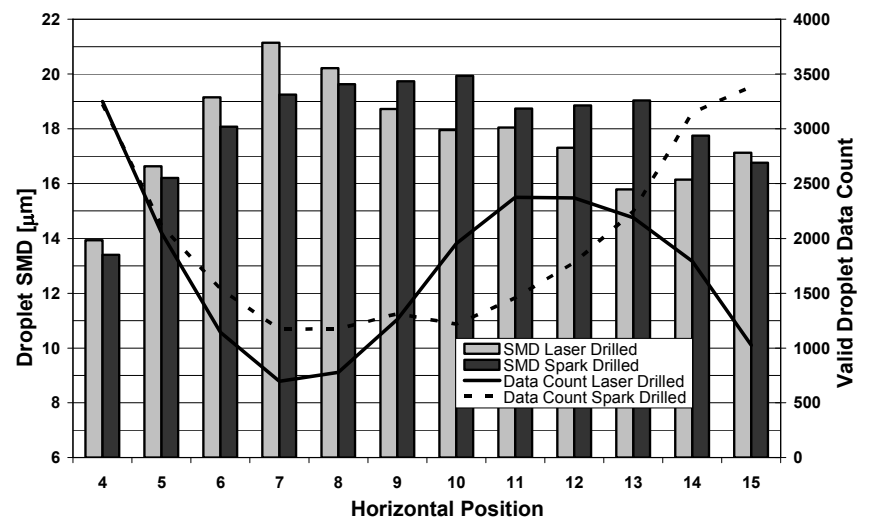

Fig. 36. Droplet SMD, $20^{\circ} \mathrm{C}, 0.5$, averaged over first $1 \mathrm{~ms}$ ASOI.

Figs. $37-40$ show the $90{ }^{\circ} \mathrm{C}$ cases at 1.0 bar and 0.5 bar downstream pressure and it can be seen that in general the SMD values were much smaller than those seen at $20{ }^{\circ} \mathrm{C}$ (Figs. 33-36) over both $4 \mathrm{~ms}$ and $1 \mathrm{~ms}$ periods, especially for the inner and outer regions of the spray plume, due to increased evaporation at the elevated fuel temperature. The Laser-drilled nozzle continues to have larger SMD values at the inner to centre regions and smaller SMD values from the centre to outer spray plume regions, compared to the sparkdrilled nozzle. For both downstream pressures and time periods there were similar trends to those seen in the $20{ }^{\circ} \mathrm{C}$ tests of Figs. 33-36. In general, at $90{ }^{\circ} \mathrm{C}$, the injector's sprays were more similar to each other than at $20^{\circ} \mathrm{C}$, for both $4 \mathrm{~ms}$ and $1 \mathrm{~ms}$ time periods. The greatest difference between injectors at $90{ }^{\circ} \mathrm{C}$ was at 1.0 bar during the first $1 \mathrm{~ms}$ (Fig. 38).

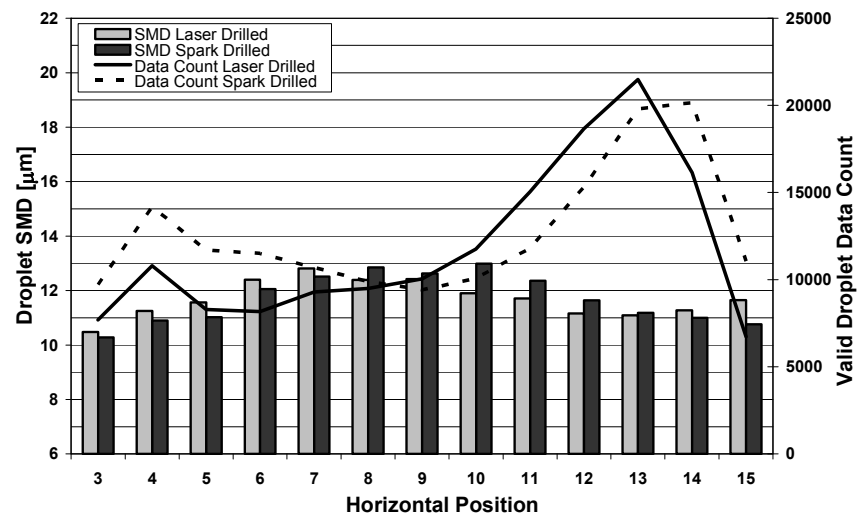

Fig. 37. Droplet SMD, $90^{\circ} \mathrm{C}, 1.0$ bar, averaged over $4 \mathrm{~ms}$ ASOI.

At the condition of $90{ }^{\circ} \mathrm{C}, 1.0$ bar shown in Fig. 37, the greatest difference between the two injector types and also the largest 
SMD value overall was at position 10; the Laser-drilled nozzle's SMD was approximately $1.1 \mu \mathrm{m}$ smaller than the spark-drilled nozzle value of $13.0 \mu \mathrm{m}$. The smallest SMD value was $10.3 \mu \mathrm{m}$, also from the spark-drilled nozzle, located at the inner plume edge at position 3. Fig. 38 shows results over the initial $1 \mathrm{~ms}$ time period where it can be seen that the droplets were larger and the differences between the injector types greater, compared to the $4 \mathrm{~ms}$ results of Fig. 37. A similar trend of differences was seen in the inner and outer regions of spray. The Laser-drilled injector's SMD was up to $2.2 \mu \mathrm{m}$ smaller at position 11 and up to $2.7 \mu \mathrm{m}$ larger at position 7 , where the maximum SMD of $17.0 \mu \mathrm{m}$ was also seen. The smallest SMD was measured at position $3 ; 11.3 \mu \mathrm{m}$ for the spark-drilled injector.

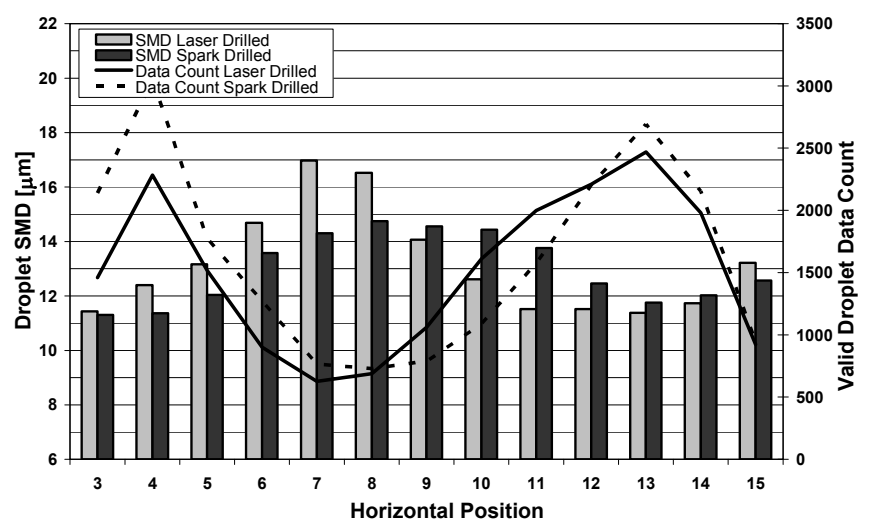

Fig. 38. Droplet SMD, $90^{\circ} \mathrm{C}, 1.0$ bar, averaged over first $1 \mathrm{~ms}$ ASOI.

Overall the smallest SMD values were found at $90{ }^{\circ} \mathrm{C}, 0.5$ bar showing the greatest level of evaporation. The results at this condition are shown in Fig. 39 and Fig. 40. The greatest difference between the injector types was seen at position 7 , in the central region of the spray plume where the Laser-drilled SMD was $1.2 \mu \mathrm{m}$ larger. The Laser-drilled injector's spray had both the minimum and maximum SMD values of approximately $9.1 \mu \mathrm{m}$ and $12.3 \mu \mathrm{m}$ at positions 15 and 9, respectively.

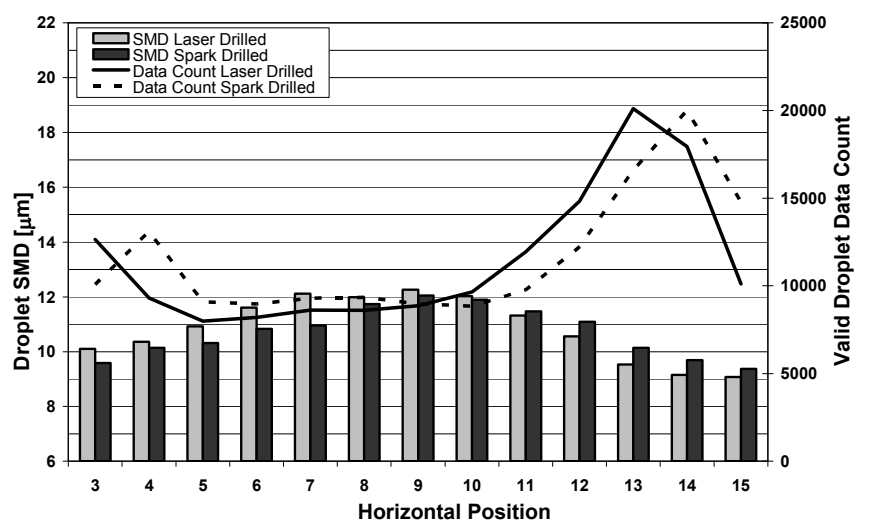

Fig. 39. Droplet SMD, $90^{\circ} \mathrm{C}, 0.5$ bar, averaged over $4 \mathrm{~ms}$ ASOI.

Fig. 40 shows that in the first $1 \mathrm{~ms}$ ASOI there was greater range of SMD from the centre to the outside regions of spray compared to the $4 \mathrm{~ms}$ period. The greatest difference between the injector types was seen at position 6 where the Laserdrilled injector's SMD was $1.3 \mu \mathrm{m}$ greater. The maximum; 14.2 $\mu \mathrm{m}$, was found at position 7, also for the Laser-drilled injector. The minimum SMD of $5.9 \mu \mathrm{m}$ was found at the outside region of the spray, at position 14, for the spark-drilled injector.

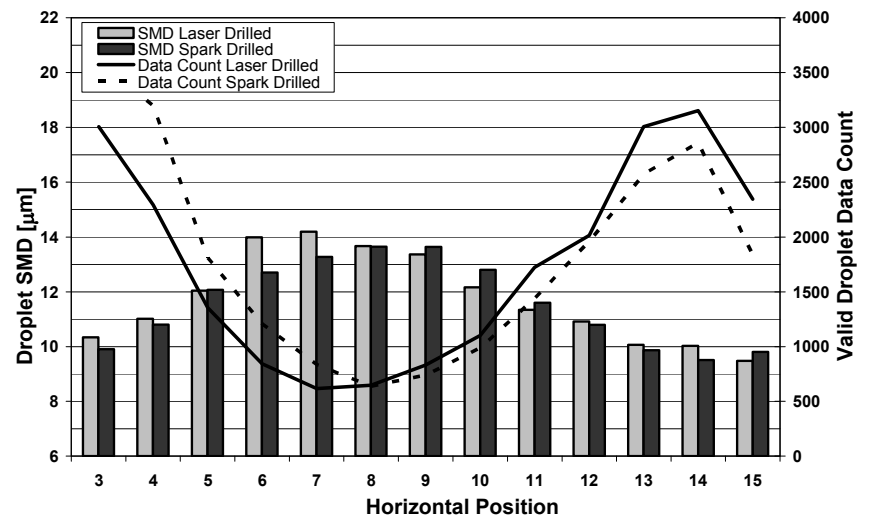

Fig. 40. Droplet SMD; $90^{\circ} \mathrm{C}, 0.5$ bar, averaged over first $1 \mathrm{~ms}$ ASOI.

Generally the Laser-drilled nozzle's valid data count in the outer region of the spray plume was much higher than that of the spark-drilled and was lower in the inner to centre regions. This may again indicate that the Laser-drilled nozzle had greater spray dispersion (i.e. more diffuse) towards the outer spray region as the PDA signal was less attenuated there.

A comparison of the overall SMD over the $4 \mathrm{~ms}$ period (i.e. SMD calculated using the whole population of droplets at all locations across the spray plume) is shown in Fig. 41 where it can be seen that there was not much difference between injectors (the error bars shown correspond to the standard deviation across all points). The greatest difference between injectors was seen at $20{ }^{\circ} \mathrm{C}, 0.5$ bar, where the Laser-drilled nozzle had an overall SMD $\sim 0.6 \mu \mathrm{m}$ smaller than the sparkdrilled nozzle. Smaller differences were observed at $20^{\circ} \mathrm{C}, 1.0$ bar where the Laser-drilled nozzle had an average SMD across the plume of $\sim 0.4 \mu \mathrm{m}$ less than the spark-drilled nozzle. At $90{ }^{\circ} \mathrm{C}$ test conditions, at both 1.0 bar and 0.5 bar, there was hardly any difference in SMD between the two injector types.

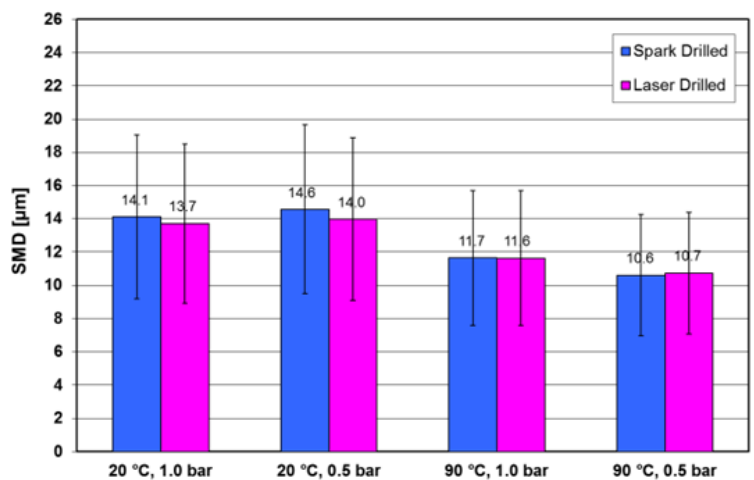

Fig. 41. Overall SMD across spray plume, averaged over 4 ms ASOI.

The overall SMD values across the spray plume over the initial $1 \mathrm{~ms}$ period are shown in Fig. 42 where it can be seen that there was more difference between the injector types than during the $4 \mathrm{~ms}$ period (Fig. 41). At $20{ }^{\circ} \mathrm{C}, 1.0$ bar the Laserdrilled spray SMD was $1 \mu \mathrm{m}$ smaller than the spark-drilled and 
$0.8 \mu \mathrm{m}$ smaller at $20{ }^{\circ} \mathrm{C}, 0.5$ bar. At $90{ }^{\circ} \mathrm{C}$ the overall SMD values of the injector types were similar, with the spark-drilled values slightly lower. It appears that the differences of SMD within the spray plume, i.e. Laser-drilled injector's larger SMD on the inside and smaller SMD on the outside of the plume, were averaged out over the whole spray region and show, overall, less significant differences between injector types.

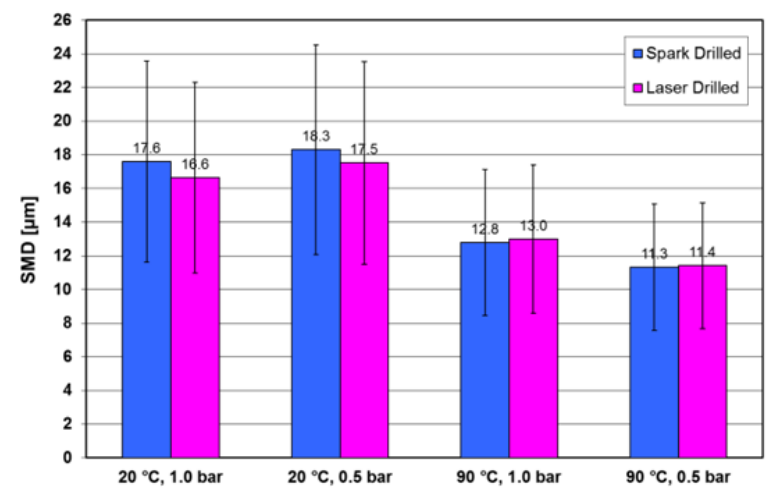

Fig. 42. Overall SMD across spray plume, averaged over $1 \mathrm{~ms}$ ASOI.

For all tests, generally the largest SMD droplet sizes were in the centre region of the spray, and the smallest sizes were in the edges of the spray due to the increased wind-induced breakup and evaporation at the inner/outer regions of the spray. A common trend seen at all test conditions is that the Laser-drilled nozzle had larger SMD droplet sizes at the inner to centre spray regions but has smaller SMD droplet sizes from the centre to outer spray regions, compared to the spark-drilled nozzle. The reasons for this are not entirely clear but it is likely that there were asymmetric flow patterns within the nozzle. The reason for lower SMD values of the Laser-drilled nozzle at the outer region of the spray plume (closest to the cylinder bore), is possibly because this outer spray region corresponds to the nozzle's internal flow region near the upper wall section of the nozzle channel and potentially there were significant differences of the internal flow field (e.g. increased cavitation) in this upper wall region. These asymmetric internal flow patterns can exist because the majority of the fuel's downwards flow enters the nozzle inlet from above, where the flow direction changes most at the hole inlet's upper section, and it is widely known that this upper section of the inlet has a dominant effect on the flow field for these nozzle types (for instance, when flow separation occurs it emanates mostly from the upper region of the inlet, where the downward flow direction is changed the most upon entering the nozzle).

The effect of downstream pressure on SMD value was different at $20{ }^{\circ} \mathrm{C}$ than that seen at $90{ }^{\circ} \mathrm{C}$ and is highlighted in both the overall droplet histogram and SMD results (Fig. 31, Fig. 41 and Fig. 42) and also the SMD results of the different positions across the plume (Figs. 33-40). At $20{ }^{\circ} \mathrm{C}$ the SMD values significantly increase at 0.5 bar, compared to 1.0 bar downstream pressure, which is likely due to the reduction of the so called wind-induced droplet breakup/evaporation, and is the result of the lower number of collisions between droplets and air molecules at the lower downstream pressure. However at $90{ }^{\circ} \mathrm{C}$, to the contrary, the SMD values significantly decrease at 0.5 bar, compared to 1.0 bar, and so it appears that at the higher temperature and lower pressure condition the reduction of wind-induced evaporation was offset completely by the thermodynamically-induced increased droplet surface evaporation caused by the higher fuel temperature and lower air pressure. A significant proportion of the gasoline's chemical components boil at temperatures lower than $90{ }^{\circ} \mathrm{C}$ and at subatmospheric pressures this vaporised proportion is increased.

Although these evaporation mechanisms seem likely, internal nozzle flow field changes and their effect on the subsequent droplet formation at reduced downstream pressure cannot be ruled out. Specifically, the degree of in-nozzle cavitation can greatly increase at higher temperatures and low downstream pressures and, in turn, increase the disruptive breakup mechanisms of the fuel spray $[5,6]$.

\section{SUMMARY AND CONCLUSIONS}

The paper presents a comparison of spray formation from injector nozzles drilled by conventional spark erosion and by latest Laser-drilling methods. The injectors were 'like-for-like' replacements, of 6-hole nozzle arrangement designed for vertical mounting in the cylinder head in close proximity to the centrally located spark plug. Electron microscopy on casts of the nozzles was initially carried out to unveil the internal geometry of the nozzle holes. Mass flow tests were carried out on both injector types for comparison. High-speed spray imaging at static engine conditions (i.e. quiescent chamber, 1.0 bar), as well as at 1750 RPM with 0.95 bar inlet pressure, were performed to characterise the mechanism of spray development at injector temperatures of $20{ }^{\circ} \mathrm{C}$ and $90{ }^{\circ} \mathrm{C}$ with 150 bar injection pressure using a multi-component gasoline fuel. Furthermore, droplet sizing with PDA quantified the SMD across the injectors' plumes with both injector temperatures at 1.0 bar and 0.5 bar ambient pressure. The main conclusions of the study are summarised as follows:

\section{Injector Nozzles:}

- Electron microscopy of casts of the nozzles showed that the Laser and spark-drilled nozzle channels had a similar inlet diameter of approximately $0.2 \mathrm{~mm}$. The nozzle inlet section of the spark-drilled injector was parallel-walled, however the Laser-drilled nozzle's inlet diverged to approximately $0.25 \mathrm{~mm}$ diameter ( $>50 \%$ area increase). Both types of nozzle expanded with a step transition to an outer cylindrical channel of $0.45 \mathrm{~mm}$ diameter; this outlet section formed most of the nozzle channel length.

- The Laser-drilled nozzle's inlet channel had significantly reduced surface roughness (within $<1 \mu \mathrm{m}$ for most of the surface) compared to the spark-drilled surface (typically 1$3 \mu \mathrm{m})$.

- Due to the design of the non-symmetric nozzle-hole pattern, the individual inlet nozzle lengths varied from hole to hole and also varied for a single nozzle hole around the channels circumference, dependent on the angle of drilling. This variation led to L/D ratios between 1 and 1.5 for the different holes. In future, L/D ratios of nozzles may also refer to $L / D$ of inlet and outlet or L/D of inlet and angle of divergence as well.

- The injected fuel mass of the Laser-drilled nozzle was higher than the spark-drilled nozzle for the same actuation 
pulse width. The greatest injected fuel mass difference between the nozzle types was at $90{ }^{\circ} \mathrm{C}$ where the Laserdrilled nozzle injected up to $1.7 \mathrm{mg}$ more per injection and up to almost $6 \%$ more fuel than the spark-drilled injector, depending on the injector pulse width. Fuel mass was reduced by about $1-1.5 \mathrm{mg}$ for both injectors when the temperature increased from $20^{\circ} \mathrm{C}$ to $90^{\circ} \mathrm{C}$.

Sprays at Quiescent Engine Conditions:

- At both $20{ }^{\circ} \mathrm{C}$ and $90{ }^{\circ} \mathrm{C}$, the Laser-drilled injector's spray appeared to be more diffuse than that of the spark-drilled injector, with increased plume width and also greater interaction of the individual spray plumes.

- $\quad$ The CoV of the Laser-drilled nozzle spray had a larger region of variation (spatially) at the spray edges, especially at $90^{\circ} \mathrm{C}$, which indicated more diffuse spray edges.

- At $90{ }^{\circ} \mathrm{C}$, the Laser-drilled injector's individual plumes appeared to collapse towards the injector body axis due to differences of induced air velocity between the centre and outside of the spray. This was a marked difference to the spark-drilled injector which did not exhibit spray collapse.

- The Laser-drilled nozzle had a more acute spray cone angle than the spark-drilled nozzle, not only for the case of 'spray collapse' at $90^{\circ} \mathrm{C}$ but also at the lower temperature of $20{ }^{\circ} \mathrm{C}$, by a margin of over 10 degrees at times. However, it was not clear whether that was related to small differences between the angles that the holes had been drilled (i.e. orientation design) with the two methods or to the mechanism of spray formation produced by the different in-nozzle geometry.

- The vertical spray penetration of the Laser-drilled nozzle was greater than the spark-drilled injector's at $20{ }^{\circ} \mathrm{C}(2-3$ $\mathrm{mm}$ ). At $90{ }^{\circ} \mathrm{C}$ it was much less (up to $12 \mathrm{~mm}$ ) than the spark-drilled nozzle. Even though the spray was collapsed at $90{ }^{\circ} \mathrm{C}$, it seemed that the increased evaporation and momentum exchange with the surrounding air reduced the spray penetration, despite the increased vertical velocity component.

\section{Sprays at Motored Engine Conditions:}

- At motored engine conditions at $90{ }^{\circ} \mathrm{C}$, the spray of both injectors appeared collapsed. The Laser-drilled nozzle exhibited a greater extent of collapse and was almost $10^{\circ}$ more acute, at times, than the spark-drilled nozzle. At 20 ${ }^{\circ} \mathrm{C}$ differences of spray half-cone angle between the injectors were not as marked as that seen for quiescent conditions and it was found that the Laser-drilled nozzle had a marginally more acute angle.

- $\quad$ The Laser-drilled nozzle had greater spray penetration and vertical velocity component than the spark-drilled at both temperature conditions. At $20^{\circ} \mathrm{C}$ the Laser-drilled nozzle had increased vertical spray penetration, typically between 2-4 $\mathrm{mm}$, and impinged on the piston $2-3^{\circ} \mathrm{CA}$ earlier.

- At $90{ }^{\circ} \mathrm{C}$, the spray penetration of the Laser-drilled nozzle was initially less than that of both injectors at $20^{\circ} \mathrm{C}$, but it

Page 21 of 22 rapidly increased due to the intake air tumble motion and hit the piston earlier than that observed at all other conditions and by $3-4^{\circ} \mathrm{CA}$ earlier compared to the sparkdrilled nozzle at the same conditions. The Laser-drilled nozzle's spray penetration was greater than the sparkdrilled nozzle's by 4-5 $\mathrm{mm}$ early on and later up to $9 \mathrm{~mm}$ as the spray approached the piston. This was a marked difference to that seen for quiescent conditions at $90{ }^{\circ} \mathrm{C}$ where the collapsed spray from the Laser-drilled nozzle had the least penetration, and it is important to note because the usual injector selection process is undertaken using data obtained for quiescent air conditions.

- The CoV spray images showed that, at both temperature conditions, the Laser-drilled nozzle's spray had more variation over a larger spatial region at the plume edges, again highlighting the more diffuse nature of this injector's spray pattern.

\section{Spray Droplet Sizing:}

- When the SMD was averaged across the plume for the 4 ms time period, the Laser-drilled nozzle had lower values than the spark-drilled nozzle at $20^{\circ} \mathrm{C}$, but only up to about $0.6 \mu \mathrm{m}$ at 0.5 bar, with a slightly lower difference of $0.5 \mu \mathrm{m}$ at 1.0 bar. There was almost no difference of SMD between the two injectors at $90{ }^{\circ} \mathrm{C}$, when averaged across the plume positions.

- When the SMD was averaged across the plume positions for the first $1 \mathrm{~ms}$ time period of injection (focusing on the spray tip and initial breakup), differences between the injector types were greater. The Laser-drilled nozzle SMD was $1 \mu \mathrm{m}$ smaller at $20^{\circ} \mathrm{C}, 1.0$ bar and $0.8 \mu \mathrm{m}$ smaller at $20{ }^{\circ} \mathrm{C}, 0.5$ bar. At $90{ }^{\circ} \mathrm{C}$, again there was not much difference between the two injector types; the Laser-drilled nozzle had marginally larger droplets by 0.1 and $0.2 \mu \mathrm{m}$ at 0.5 bar and 1.0 bar, respectively.

- A common trend seen at all conditions was that the Laserdrilled nozzle had larger SMD at the inner to centre spray region, but it had smaller SMD from the centre to outer spray region. This may be related to the in-nozzle geometry characteristics and significant differences of in-nozzle flow field, particularly increased cavitation, in the region of the upper inlet corner and upper wall inside the nozzle hole.

- The similarity of overall SMD values (for all positions) between the two injector types indicate that differences in droplet sizes at individual positions (i.e. between the inner and outer spray regions) essentially average out, leading to not much difference in overall SMD.

The study of nozzle-hole geometry differences is important as they are a key factor determining the internal flow field and characteristics of primary spray formation, e.g. classical spray theory asserts that turbulence within the nozzle creates surface waves and instabilities on exit, leading to liquid breakup. Furthermore, the presence of multi-phase flow already inside the nozzle e.g. from cavitation effects, is already known to have a marked effect on the spray breakup. Classical theories have not been developed on the basis of multi-phase flows inside the nozzle, or have not explicitly included fast disruptive 
evaporation effects of hot fuels upon their injection into a low pressure environment. The observed more diffuse nature of the Laser-drilled nozzle's spray was due to internal-hole geometry differences which both changed the near nozzle angle of spray plume ejection and modified the internal flow field, probably accompanied with increase of cavitation that added further to angle increase and radial momentum effects. In any case, the more diffuse spray pattern was not necessarily associated with large difference in droplet sizes.

The research work has been expanded and it currently focuses on differences of spray formation between the two injectors using fuels of various properties. This can shed more light on in-nozzle two-phase flow differences between the injectors and decouple some of the observed effects.

\section{ACKNOWLEDGEMENTS}

The authors wish to thank the EPSRC instrument pool for provision of equipment and their technical advice. Financial support by the EPSRC via a CASE award is also gratefully acknowledged. UCL's Department of Archaeology are gratefully acknowledged for use of their scanning electron microscopes and assistance.

\section{REFERENCES}

1. Callies, G., Willert, M., Osswald, K., "Method and Device for Laser Drilling in a Process Gas Atmosphere", Patent No US 7,301,121 B2, 2007.

2. Whitaker, P., Kapus, P., Ogris, M., Hollerer, P., "Measures to Reduce Particulate Emissions from Gasoline DI Engines", SAE Paper 2011-01-1219, 2011.

3. Zhang, M., Drake M., Peterson, K., "Simultaneous HighSpeed Imaging of Fuel Spray, Combustion Luminosity, and Soot Luminosity in a Spray-Guided Direct Injection Engine with Different Multi-Hole Fuel Injectors" Proceedings of the ASME 2013 Internal Combustion Engine Division Fall Technical Conference, Paper ICEF2013-19066, 2013.

4. Das, S., Chang, S., and Kirwan, J., "Spray Pattern Recognition for Multi-Hole Gasoline Direct Injectors Using CFD Modeling" SAE Paper 2009-01-1488, 2009.

5. Serras-Pereira, J., van Romunde, Z., Aleiferis, P.G., Richardson, D., Wallace, S., Cracknell, R.F., "Cavitation, Primary Break-up and Flash Boiling of Gasoline, isoOctane and $n$-Pentane with a Real-Size Optical DirectInjection Nozzle", Fuel, 89:2592-2607, 2010.

6. Aleiferis, P.G., Serras-Pereira, J., Augoye, A., Davies, T.J., Cracknell, R.F., Richardson, D., "Effect of Fuel Temperature on In-Nozzle Cavitation and Spray Formation of Liquid Hydrocarbons and Alcohols from a Real-Size Optical Injector for Direct-Injection Spark-Ignition Engines", Int. J. Heat Mass Transfer, 53:4588-4606, 2010.

7. Macián, V., Bermudez, V., Payri, R., Gimeno, J., "New Technique for Determination of Internal Geometry of a Diesel Nozzle with the Use of Silicone Methodology", Exp. Tech., 27:39-43, 2003

8. Butcher, A.J., Aleiferis, P.G., Richardson, D., "Development of a Real-Size Optical Injector Nozzle for Studies of Cavitation, Spray Formation and Flash Boiling at Conditions Relevant to Direct-Injection Spark-Ignition Engines”, Int. J. Eng. Res., 14:557-577, 2013.
9. Benajes, J., Pastor, J.V., Payri, R., Plazas, A.H., "Analysis of the Influence of Diesel Nozzle Geometry in the Injection Rate Characteristic", Trans. ASME, J. Fluids Eng., 126:63-71, 2004.

10. van Romunde Z.R., Aleiferis P.G., "Effect of Operating Conditions and Fuel Volatility on Development and Variability of Sprays from Gasoline Direct-Injection MultiHole Injectors", Atom. Sprays, 19:207-34, 2009.

11. van Romunde, Z.R., Aleiferis P.G., Cracknell, R.F., Walmsley H.L., "Effect of Fuel Properties on Spray Development from a Multi-Hole DISI Engine Injector", Trans. SAE, J. Engines, 116(3):1313-31 Paper 2007-014032, 2007.

12. Aleiferis, P.G. and van Romunde, Z.R., "An Analysis of Spray Development with iso-Octane, $n$-Pentane, Gasoline, Ethanol and $n$-Butanol from a Multi-Hole Injector under Hot Fuel Conditions", Fuel, 105:143-168, 2013.

13. Behringer, M.K., Aleiferis, P.G., OudeNijeweme, D., Freeland, P., "Spray Formation from Spark-Eroded and Laser-Drilled Injectors for DISI Engines with Gasoline and Alcohol Fuels", SAE International Journal of Fuels and Lubricants, 7, SAE Paper 2014-01-2745, 2014.

14. Gandhi, A. H., Meinhart, M., "Fuel Injector Flow Rate Analysis for the Duratec 35 EcoBoost Engine", SAE Paper 2009-01-1505, 2009.

15. Serras-Pereira, J., Aleiferis, P.G., Richardson, D., Wallace S., "Mixture Formation and Combustion Variability in a Spray-Guided DISI Engine", Trans. SAE, J. Engines, 116(3):1332-56, Paper 2007-01-4033, 2007.

16. Serras-Pereira, J., Aleiferis, P.G., Richardson, D., Wallace S., "Characteristics of Ethanol, Butanol, iso-Octane and Gasoline Sprays and Combustion from a Multi-Hole Injector in a DISI Engine", SAE Int. J. Fuels Lubr., 1:893909, Paper 2008-01-1591, 2008.

17. Serras-Pereira J., Aleiferis, P.G., Richardson, D., "An Analysis of the Combustion Behaviour of Ethanol, Butanol, iso-Octane, Gasoline and Methane in a Direct-Injection Spark-Ignition", Combust. Sci. Tech., 185:484-513, 2013.

18. Serras-Pereira J., Aleiferis, P.G., Richardson, D., "Characterisation of Flame Development with Ethanol, Butanol, iso-Octane, Gasoline and Methane in a DirectInjection Spark-Ignition Engine", Fuel, 109:256-278, 2013.

19. Serras-Pereira J., Aleiferis, P.G., Richardson, D., "Imaging and Heat Flux Measurements of Wall Impinging Sprays of Hydrocarbons and Alcohols in a Direct-Injection SparkIgnition Engine", Fuel, 91:264-297, 2012.

20. Serras-Pereira, J., Aleiferis, P.G., Walmsley, H.L., Davies, T.J., Cracknell, R.F., "Heat Flux Characteristics of Spray Wall Impingement with Ethanol, Butanol, iso-Octane, Gasoline and E10 Fuels", Int. J. Heat Fluid Flow, 44:662683, 2013

21. Aleiferis, P.G., Serras-Pereira, J., van Romunde, Z.R., Caine J., Wirth, M., "Mechanisms of Spray Formation and Combustion from a Multi-Hole Injector with E85 and Gasoline", Comb. Flame, 157:735-56, 2010.

\section{CONTACT INFORMATION}

Prof. Pavlos Aleiferis

Department of Mechanical Engineering

University College London

Torrington Place, London WC1E 7JE, UK

E-mail p.aleiferis@ucl.ac.uk 